The INL is a

U.S. Department of Energy

National Laboratory

operated by

Battelle Energy Alliance

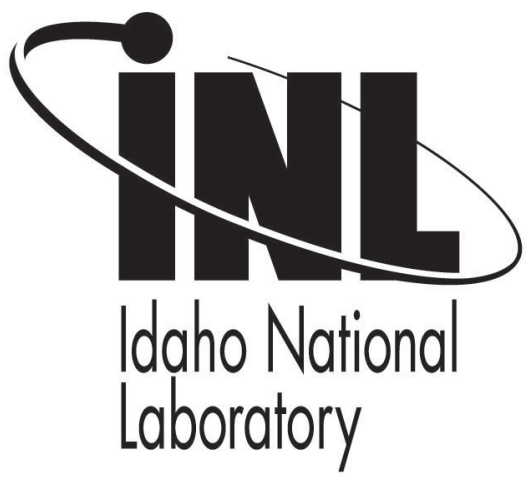

INL/CON-12-25806

PREPRINT

\section{Estimation of the}

Performance of Multiple

Active Neutron

Interrogation Signatures

for Detecting Shielded

HEU

\section{IEEE 2012 Nuclear Science Symposium}

David L. Chichester

Scott J. Thompson

Scott M. Watson

James T. Johnson

Edward H. Seabury

\section{October 2012}

This is a preprint of a paper intended for publication in a journal or proceedings. Since changes may be made before publication, this preprint should not be cited or reproduced without permission of the author. This document was prepared as an account of work sponsored by an agency of the United States Government. Neither the United States Government nor any agency thereof, or any of their employees, makes any warranty, expressed or implied, or assumes any legal liability or responsibility for any third party's use, or the results of such use, of any information, apparatus, product or process disclosed in this report, or represents that its use by such third party would not infringe privately owned rights. The views expressed in this paper are not necessarily those of the United States Government or the sponsoring agency. 


\title{
Estimation of the Performance of Multiple Active Neutron Interrogation Signatures for Detecting Shielded HEU
}

\author{
David L. Chichester, Senior Member, IEEE, Scott J. Thompson, Scott M. Watson, James T. Johnson, and Edward H. \\ Seabury
}

\begin{abstract}
A comprehensive modeling study has been carried out to evaluate the utility of multiple active neutron interrogation signatures for detecting shielded highly enriched uranium (HEU). The modeling effort focused on varying HEU masses from $1 \mathrm{~kg}$ to $20 \mathrm{~kg}$; varying types of shields including cement, wood, polyethylene, aluminum, and steel; varying depths of the HEU in the shields, and varying engineered shields immediately surrounding the HEU including steel, lead, and cadmium. Neutron and gamma-ray signatures were the focus of the study and false negative detection probabilities versus measurement time were used as a performance metric. To facilitate comparisons among different approaches an automated method was developed to generate receiver operating characteristic (ROC) curves for different sets of model variables for multiple background count rate conditions. This paper summarizes results or the analysis, including laboratory benchmark comparisons between simulations and experiments.
\end{abstract}

\section{INTRODUCTION}

$\mathrm{D}$ etecting well-shielded special nuclear material (SNM), up close or from standoff locations, is difficult. Passive measurements can detect some types of SNM under some conditions with shielding; however, they are not generally an effective technique for unequivocally identifying the presence of SNM under heavily shielded conditions.[1] To effectively scan well-shielded objects for SNM something must be done to enhance the natural rate of signature emission; active interrogation is one promising approach to achieve this goal. Active interrogation (alternatively called active inspection or active detection) is a nondestructive measurement technique capable of detecting shielded highly enriched uranium (HEU) under conditions where it is very difficult for passive measurements to succeed. However, the performance limits of active interrogation for detecting shielded HEU are also not limitless.[2]

The performance of passive radiation detection systems, whether detecting photons or neutrons, is inherently limited

Manuscript received November 11, 2012. Idaho National Laboratory is operated for the U.S. Department of Energy by Battelle Energy Alliance under DOE contract DE-AC07-05-ID14517.

D. L. Chichester (telephone: 208-526-8920, e-mail: david.chichester@inl.gov), S. J. Thompson (telephone: 208-526-1459, e-mail: scott.thompson@inl.gov), S. M. Watson (telephone: 208-525-0572, e-mail: scott.watson@inl.gov), J. T. Johnson (telephone: 208-525-0572, email:james.johnson@inl.gov), and E. H. Seabury (telephone: 208-526-5303, email:edward.seabury@inl.gov) are all with Idaho National Laboratory, Idaho Falls, Id., 83415, USA.

The author's would like to acknowledge the support of the Office of Nonproliferation and Verification Research and Development (NA-22) of the National Nuclear Security Administration, United States Department of Energy, for this work. by the intensity of the radiation source (SIGNAL) and the intensity of background and interferences (NOISE), this is also true for active interrogation systems. In all but the most simplistic of detection scenarios the primary challenge for detecting shielded SNM using passive measurements is that the observed signature of the materials is small, perhaps less than that of the local background radiation. For passive measurements this can be a great challenge because natural background radiation is so variable from place to place, and even over time in the same place. One of the primary advantages with using active interrogation, versus passive screening measurements, is the ability to take 'background' measurements before interrogation begins. Passive screening measurements can use background readings from nearby locations, or from simulations, but typically the specific measurement-location background cannot be directly determined. Active interrogation radiation sources can also induce background signals. However, through judicious selection of radiation sources and detectors, the impacts of these active interferences may often be eliminated, or at least known.

A considerable amount of prior work has been published exploring the use of active interrogation methods for detecting shielded SNM.[3-8] Many different combinations of irradiation source and detected signature have been explored. In most early work, research focused on choosing one type of irradiation source and one signature to be measured.[9] More recent work has recognized the value of measuring multiple signatures simultaneously. Swanekamp et al. have presented compelling research about the value of using one single, intense pulse of $\mathrm{x}$-rays to serve as an active interrogation source for detecting SNM.[10] They have shown that this approach, which can in principle support the collection of data from the prompt-fission (including die-away, if present) and $\beta$-delayed neutron signatures, has the potential to significantly improve detection capabilities versus more traditional, pulsed linear electron accelerator (LINAC) based active bremsstrahlung interrogation (ABI) approaches. Gribkov et al. have illustrated comparable advantages for using singleshot, nanosecond pulsed neutron sources.[11] Tartaglione et al., and later Gribkov et al. and others have also illustrated the potential value time-of-flight analyses can have when interpreting active interrogation signatures, including its use with repetitively-pulsed neutron sources.[11-13]

Shaw et al. have presented data showing how x-ray radiography may be used to reduce the scanning times needed for cargo screening when using neutron interrogation measurements focused on differential die-away analysis.[14] 
Others have discussed similar approaches for combining prompt and delayed fission signatures for SNM detection.[1517] Hausladen et al. have shown the value of using an associated-particle electronic neutron generator (ENG) for interrogation, combining fast-neutron radiography with coincident-neutron detection for fission mapping.[18] Cester et al. have shown an alternative approach for combining multiple active interrogation signatures, merging time correlated data from an associated-particle ENG with gammaray spectroscopy..[19]

Research and development activities exploring the practical applications of active interrogation, using radioisotope neutron sources, ENGs, and high-energy bremsstrahlung sources have been underway at Idaho National Laboratory (INL) for over two decades.[20-23] This prior work has explored the use of active interrogation methods for detecting and characterizing toxic industrial chemicals, narcotics, chemical warfare materiel, currency, high explosives, and special nuclear material (SNM). In this paper we report the results of a recently completed simulation and modeling campaign exploring the utility of portable ANI methodologies for detecting shielded HEU. Focusing on 'portable' approaches, the project was limited to considering portablescale ENG interrogation sources and detector components with sizes that can be carried by one or two people. However, scaling to larger-intensity ENGs or larger-area/higherefficiency detectors is readily possible.

The goal of the project was to systematically study the utility of many of the different active interrogation signatures which can be measured, to compare the usefulness of these different signatures across a broad spectrum of shield scenarios, and to generate a basis of knowledge for assessing the outer-limits of the applicability of portable ANI methods for detecting shielded HEU. Secondary goals of the project were a) to generate a post-processing toolkit to facilitate more detailed, predictive analyses of the capabilities of proposed and future active interrogation systems and $b$ ) to provide a framework for assessing how improved instrumentation (e.g., new detectors, novel radiation sources) and methodologies could be used to improvise the capabilities of active interrogation for detecting shielded HEU.

\section{ApProAch to the Problem}

When considering the utility of active interrogation systems it is important to consider scenarios where it would indeed be difficult, if not impossible, for passive screening to succeed. Initial research demonstrating new ideas in this field frequently presents data to show efficacy of active interrogation using simple scenarios; often these scenarios represent cases, however, where passive screening alone would be adequate for detecting shielded uranium.[23-25] This project was specifically focused to examine shielding situations where the passive gamma-ray signatures of HEU are attenuated to such a degree that a long-dwell ( $>30$ minute) assay using a high-sensitivity, high-resolution gamma-ray spectrometer would not detect the higher-energy gamma-rays lines from ${ }^{238} \mathrm{U}$. (This implies single or multi-layer shields with the equivalent of $>100 \mathrm{~g} \mathrm{~cm}^{-2}$ shielding for low-Z shielding, $>60 \mathrm{~g} \mathrm{~cm}^{-2}$ for mid-Z shielding, and/or $>10-20 \mathrm{~g}$ $\mathrm{cm}^{-2}$ for high-Z shielding.)

\section{A. Simulation Parameters}

Recognizing that a comprehensive experimental program would be an impractical approach for trying to understand the performance capabilities and limits of active interrogation for detecting shielded HEU, simulation and modeling is often relied on for parametric studies of the method.[26-29] For this project simulations were carried out to assess methods for detecting the induced fission signatures of neutron and photon emission from HEU in a variety of $3 \times 3 \times 3 \mathrm{~m}^{3}$ bulk shields including wood, cement, polyethylene, and low density aluminum and steel. This approach, using the MCNP5 and MCNPX radiation transport codes, has been presented previously.[30-32] These large-volume shields were not chosen to be specifically representative of particular scenarios (cargo containers, vehicles, buildings, etc.) but rather to provide a generalized representation of several shield configurations that can be very difficult for both passive screening and ANI to deal with (to successfully detect HEU).

The following parameters were examined for this project.[30]

- Interrogation source:

- DD106: Deuterium-deuterium (DD-) ENG $\left(E_{n}=\right.$ $2.5 \mathrm{MeV}$ ) with yield of $10^{6} \mathrm{n} \mathrm{s}^{-1}$

○ DD10 8 : DD-ENG with yield of $10^{8} \mathrm{n} \mathrm{s}^{-1}$

DD $10^{8}$ : DT-ENG with yield of $10^{8} \mathrm{n} \mathrm{s}^{-1}$

- Bulk shields:

○ Air

○ Cement, $2.3 \mathrm{~g} \mathrm{~cm}^{-3}$

○ Wood, $0.45 \mathrm{~g} \mathrm{~cm}^{-3}$

○ Polyethylene, $0.95 \mathrm{~g} \mathrm{~cm}^{-3}$

○ Aluminum, $0.6 \mathrm{~g} \mathrm{~cm}^{-3}$

- Steel, $0.6 \mathrm{~g} \mathrm{~cm}^{-3}$

- Engineered (near) shields:

o None

○ $5 \mathrm{~cm}$ steel

○ $5 \mathrm{~cm}$ lead

○ $0.1 \mathrm{~cm}$ cadmium

○ $0.1 \mathrm{~cm}$ cadmium and $5 \mathrm{~cm}$ lead

- HEU mass:

- $1,2,5,10$, and $20 \mathrm{~kg}$

- The ${ }^{235} \mathrm{U}$ enrichment was $90 \%$ in all cases.

- HEU depth into the shield:

$\circ \quad 0.2,0.3,0.4,0.5,0.6,0.7,0.8,0.9$, and $1 \mathrm{~m}$.

○ The interrogation source was always centered on the HEU location at the face of the bulk shield.

DD-ENGs with a yield of $10^{6} \mathrm{n} \mathrm{s}^{-1}$ and DT-ENGs with a yield of $10^{8} \mathrm{n} \mathrm{s}^{-1}$ are currently available. However, it became clear during this project that the range of applicability of the DD $10^{6}$ ENG, with this very low neutron yield, would be minimal. Therefore, the decision was made to also consider a higher-yield DD ENG, anticipating that at some time in the future higher-yield, portable DD ENGs may exist. We did not, however, consider commensurately higher DT ENGs because the practical limit for operating ENGs in the field, for personnel safety, is in the $10^{8} \mathrm{n} \mathrm{s}^{-1}$ to $10^{9} \mathrm{n} \mathrm{s}^{-1}$ range.

\section{B. Detectors}

For practical constraints we limited the selection of detectors used in this investigation to the following, commonly used classes of instruments. 
- Conceptual polyethylene-moderated array of ${ }^{3} \mathrm{He}$ detectors: In the models an array of three detectors modules was used. Each module contained four, 4atm. ${ }^{3} \mathrm{He}$ detectors embedded in a polyethylene. The detector modules were placed side-by side and had a total active surface area of XX cm. Each module was individually wrapped in neutron absorbing material ( $\mathrm{Cd}$ and $\mathrm{B}$ ) to eliminate sensitivity to room-return thermal neutrons that can linger in an area for hundreds of milliseconds after each pulse from an ENG. The inherent die-away time of the neutron modules was $31 \mu \mathrm{s}$. The efficiency of the modules for detecting unmoderated, fission-spectrum neutrons was $8.5 \%$, the detector area was $0.19 \mathrm{~m}^{2}$. The simulations tallied actual ${ }^{3} \mathrm{He}$-capture events in a model of the detector array. The detector array was located $0.1 \mathrm{~m}$ from the outside of the shield area, 0.1 $\mathrm{m}$ to one side of the ANI source.[30]

- Ideal neutron detectors: To allow a more universal comparison, the ${ }^{3} \mathrm{He}$ detector results from the 'concpetual' detector were also scaled to represent an idealized detector with a $0.25 \mathrm{~m}^{2}$ detection area with $25 \%$ intrinsic efficiency for fission spectrum neutrons.

- Liquid-scintillator detector: For the simulations an idealized liquid scintillator system with a total active area of $0.25 \mathrm{~m}^{2}$ was used for analysis. The simulations calculated the energy- and timedependent neutron and gamma-ray flux values at a measurement position $0.1 \mathrm{~m}$ from the outside of the shield area, $0.1 \mathrm{~m}$ to one side of the ANI source.[30] For neutron detection an energy-dependant efficiency function, corresponding to the measured response of a $7.62-\mathrm{cm} \times 7.62-\mathrm{cm} \varnothing$ liquid scintillator cell filled with EJ-309 scintillator, was applied to the flux tallies.[33] For photon detection a simplified scaling efifeicny of $25 \%$ was applied for all events with photons more than $3 \mathrm{MeV}$ in energy.

A ${ }^{3} \mathrm{He}$ detector array was chosen because of its exceptional performance for this application. Recent shortages of ${ }^{3} \mathrm{He}$ may make it impractical under some circumstances. However, despite dire predictions to the contrary, the material is not yet obsolete and it may likely be available for the applications described in this project. Regardless, however, the scaling relationship illustrated with the 'ideal neutron detector' is technology independent, in accordance with the proscribed die-away, efficiency, and sensitive area definitions. Alternative ${ }^{3} \mathrm{He}$ detector technologies could also be used.

Other photon detectors besides the liquid scintillator described here could be used. However, the gamma-ray detection results presented here for the LS are not (unlike the neutron performance of the LS detector) actually detector specific. The results presented here could be scaled to any other detector type with a combined efficiency/area combination (absolute efficiency) with performance similar to that of the 'LS' system.

\section{Signatures Studied}

Staying within the constraints of instruments and methods suitable for use in the field, as part of a portable system,
Analyses were made to characterize the following measurements of induced-fission signatures. All results were simulated for a total one-hour duration.

- Beam-on prompt neutrons - high-energy: Operate the DD $10^{6}$ or DD $10^{8}$ ENG in continuous mode (no pulsing), use the LS detector to measure energydeposition events corresponding to an energy greater than $2.5 \mathrm{MeV}$ (a $3 \mathrm{MeV}$ threshold was used). This approach is similar in concept to priro work reported elsewhere using a low-energy accelerator.[34]

- Beam-on prompt neutrons - die-away: Operate the DD $10^{6}, \mathrm{DD} 10^{8}$, or DT $10^{8} \mathrm{ENG}$ at a pulse rate of $100 \mathrm{~Hz}$ with a $10 \%$ duty cycle, use the ${ }^{3} \mathrm{He}$ detector array to measure die-away neutrons (if present). The presence of die-away neutrons is declared if a change in recovery time of the detectors was observed above a threshold, by monitoring a change in the detectorinherent die-away time. If die-away was observed a fit was made to the die-away rate and the signature window was extended until the slope of the die-away reached the background rate. For cases with very large signatures this cut-time would under-count the signal. However, in these cases 'nuclear material detection' was always declared within the first 1second of a measurement.

- Beam-on $\beta$-delayed neutrons: Operate the DD $10^{6}$, DD $10^{8}$, or DT $10^{8} \mathrm{ENG}$ at a pulse rate of $100 \mathrm{~Hz}$ with a $10 \%$ duty cycle, use the ${ }^{3} \mathrm{He}$ detector array to measure $\beta$-delayed neutrons (if present). $\beta$-delayed neutrons were defined with a window starting from 5 $\mathrm{ms}$ and going to the end of the pulse period.

- Beam-on total neutrons: Operate the $\mathrm{DD} 10^{6}$, DD $10^{8}$, or DT $10^{8} \mathrm{ENG}$ at a pulse rate of $100 \mathrm{~Hz}$ with a $10 \%$ duty cycle, use the ${ }^{3} \mathrm{He}$ detector array to measure all the neutrons immediately after the end of each pulse. This signature is the combination of dieaway and delayed neutrons. For cases with die-away the performance of this signature mirrors the dieaway performance. However, for cases without dieaway, this signature removes the bias from the delayed-neutron signature due to waiting to begin counting signal until $5 \mathrm{~ms}$. The total neutron signal, which includes data while the detector is still recovering, is not always the best signal, since the background rate (and thus the uncertainty in the measurements) while the detector is recovering is also higher. We chose to separate the die-away and delayed components since this has often been reported in the literature when detectors with long inherent die-away times have been used.[35]

- Beam-off $\beta$-delayed neutrons: Operate the DD $10^{6}$, $\mathrm{DD} 10^{8}$, or DT $10^{8} \mathrm{ENG}$ at a pulse rate of $100 \mathrm{~Hz}$ with a $10 \%$ duty cycle for $120 \mathrm{~s}$, then turn the ENG off and use the ${ }^{3} \mathrm{He}$ detector array to measure neutrons for 100 seconds - repeat for one hour.

- Beam-off $\beta$-delayed gamma rays: Operate the $\mathrm{DD} 10^{6}$ or $\mathrm{DD} 10^{8}$ at a pulse rate of $100 \mathrm{~Hz}$ with a $10 \%$ duty cycle for $100 \mathrm{~s}$, then turn the ENG off and use the LS detector to measure photons with a 
deposited energy of greater then $3 \mathrm{MeV}$ for $100 \mathrm{~s}-$ repeat for one hour. Note: DT neutrons are capable of opening the ${ }^{16} \mathrm{O}(\mathrm{n}, \mathrm{p}){ }^{16} \mathrm{~N}$ reaction, which yields delayed gamma-rays $>3 \mathrm{MeV}$ with a $7.13 \mathrm{~s}$ half life. These gamma rays produce a non-trivial, itemspecific background interference. Because of this, DT irradiation was not assessed for the $\beta$-delayed gamma-ray signature.

\section{Figure of Merit}

A measurement-to-measurement comparison should take into account all circumstances, providing a complete evaluation of overall "detectability." The receiver operating characteristic (ROC) analysis, commonly employed in medical research communities, is just such a method that graphically summarizes the four detection outcome probabilities for all possible decision conditions.

- True Negative (TN)- The hypothesis that there is no threat is accepted, and truly no threat exists.

- True Positive (TP)- The hypothesis is rejected in favor of the alternative that a threat is present, and truly a threat exists.

- False Positive (FP)- The hypothesis is rejected when no threat truly exists. This is also referred to as Type I Error or a false alarm and is often denoted by the character $\alpha$.

- False Negative (FN)- The hypothesis is accepted and a threat truly exists. This is also referred to as Type II Error or a missed detection and is often denoted by the character $\beta$.

The ROC metric is a well-known method for assessing the performance of ANI systems.[10,36] The same approach has been used for this project, and has been presented previously.[30]

A ROC curve is essentially a plot of false-positive versus true-positive detection rates, yet the complementary nature of the four detection outcome probabilities allows for the concurrent demonstration of false-negative and true-negative rates as well. Examples of the ROC method of presenting outcome probabilities are shown in Fig. 1 for a case with a mean background signal of 400 counts, demonstrating the effects of both measurement uncertainty and mean value of the shape of a ROC curve. Absolute detection can be defined as having a $100 \%$ probability rate for both of the true detection outcomes with no chance for the false outcomes. On a standard ROC scale this is represented by the upper-left most corner of the plot. Hence, a ROC curve's level of concavity in this quadrant is indicative of the corresponding measurement scenario's sensitivity. The ROC analysis method can also be useful in determining an application appropriate decision level, since each point on the curve corresponds to a single decision level setting. Advancing the decision is equivalent to a movement in outcome probability space, along the ROC curve, toward the false positive-true positive origin. This analysis can therefore be used as a guide for adjusting the decision to meet the situational requirements of a given measurement.

As a detection measurement progresses in duration, signature count totals increase and uncertainty in detection rates falls. It is therefore possible to evaluate how detection outcome probabilities evolve with measurement length, and to assess and compare the time sensitivity of different signatures. Simulated measurement probability distributions were generated in the course of this work for incrementally increasing inspection durations.
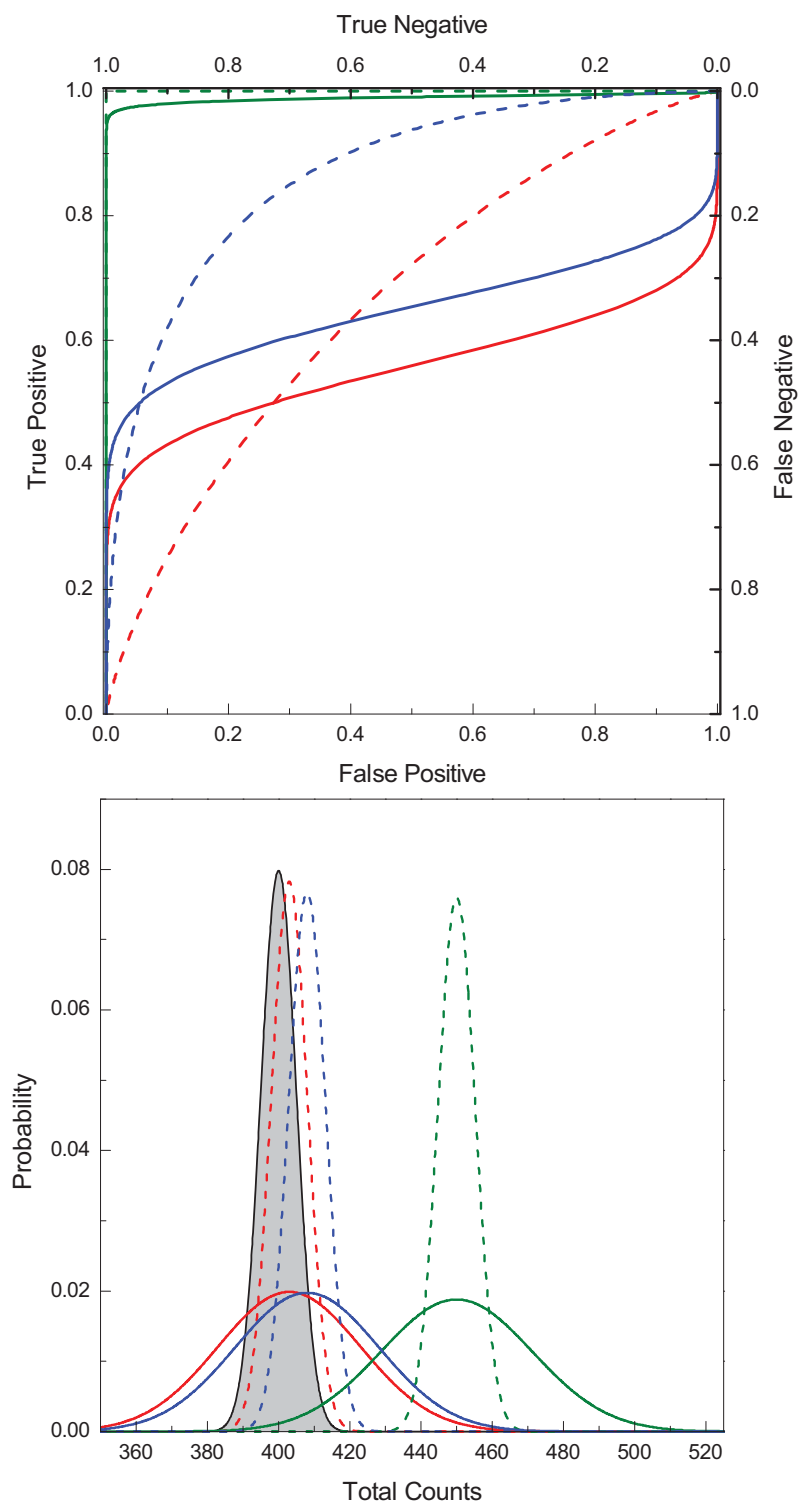

Fig. 1 Six receiver operating characteristic (ROC) curves (top) generated from six signal + background probability distributions of varying mean and uncertainty (bottom). The grey distribution in the lower plot is the background for which all other distributions are weighed against.

For this project the time evolution of measurement confidence was used for assessing detection performance of different irradiation source/detector/signature combinations. At each time instance for which a measurement distribution is generated, a decision level is determined for a requisite FP outcome probability and the corresponding $\mathrm{FN}$ rate is calculated.

The figure of merit (FOM) used to compare these scenarios for this project is the measurement time required for the miss rate to fall below a certain acceptable value using a decision level governed by false-alarm requirements. In Fig. 2 is a plot of FOM values for reaching a FN rate of $0.1 \%$ with a 
INL-CON-12-2580థ

decision level required for a maximum FP rate of $1.0 \%$. Values in the plot are for interrogating a cement shield using a DT-ENG (14.1 MeV neutrons). Each solid-line curve in the plot represents a different mass of HEU hidden in the cement at different depths, while dotted lines of the same color represent the same mass of HEU being measured using either a different FN threshold or different FN threshold and a larger-area detector. Data in this plot are presented as a function of cement shielding depth. For the results reported here, FP rates were held at either $1 \%$ or $10 \%$, or $1-, 2-$, or $3-\sigma$ levels, while the FOM was the time needed for the FN rates to fall below either $0.1 \%$ or $1 \%$. In all cases, the background signal uncertainty is set at a level that would be achieved with a 1-hour determination. A 1-hour background acquisition was assumed as a reasonable estimate of the time needed to set-up and prepare a portable ENG system for operation, inclduing clearing an unknown area of personnel. For the ${ }^{3} \mathrm{He}$ instruments two background levels were considered, $0.5 \mathrm{~s}^{-1}$ (lower bound of reasonable levels) and $5 \mathrm{~s}^{-1}$ (upper bound of reasonable levels).

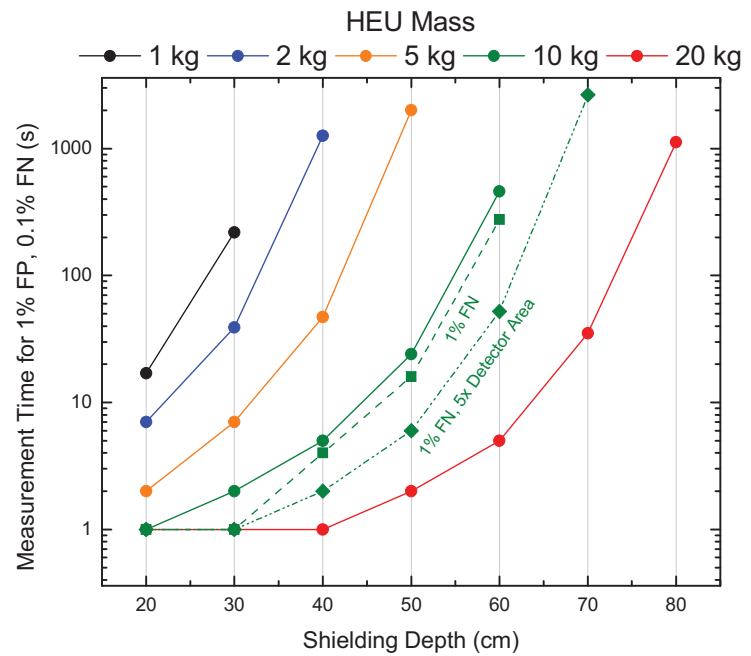

Fig. 2 Measurement times needed to detect different masses of HEU hidden at different depths inside a cement shield. The measurements are based on using a DT-ENG as the interrogation source and the polyethylenemoderated, shielded array of He-3 neutron detectors for measuring betadelayed neutrons in-between pulses of the DT-ENG.

\section{Results AND DISCUSSION}

This section provides examples of the simulation results for time-to-detect values in cement during 1-hr analyses, final results after 1-hr measurements in air and polyethylene, and illustrates the scaling effect for the ideal neutron detectors.

\section{A. Time Evolution - Cement $-{ }^{3}$ He Measurements}

Time-to-detect results for the cement case for the signatures measured using the conceptual ${ }^{3} \mathrm{He}$ detector arrays are presented in Fig. 3 through Fig. $7 . \quad$ These figures indicate when the FN and FP requirements are satisfied (detection is achieved) under these scenarios as they evolve over time during the course of one-hour measurements.
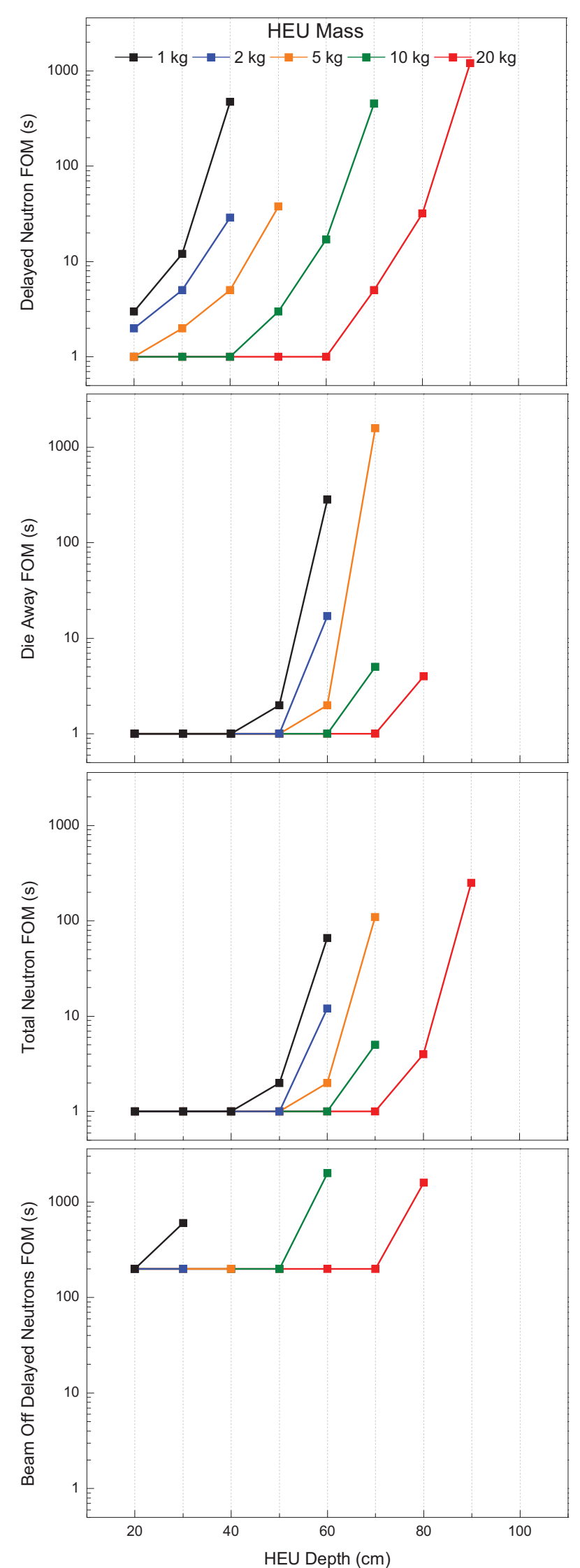

Fig. 3 FOM values for the cement bulk shield with no near shield. Values assume $1 \%$ false alarm (FP) and $1 \%$ miss rates (FN), with a background count rate of 300 counts per minute per detector; DT $10^{8}$. 
INL-CON-12-25806
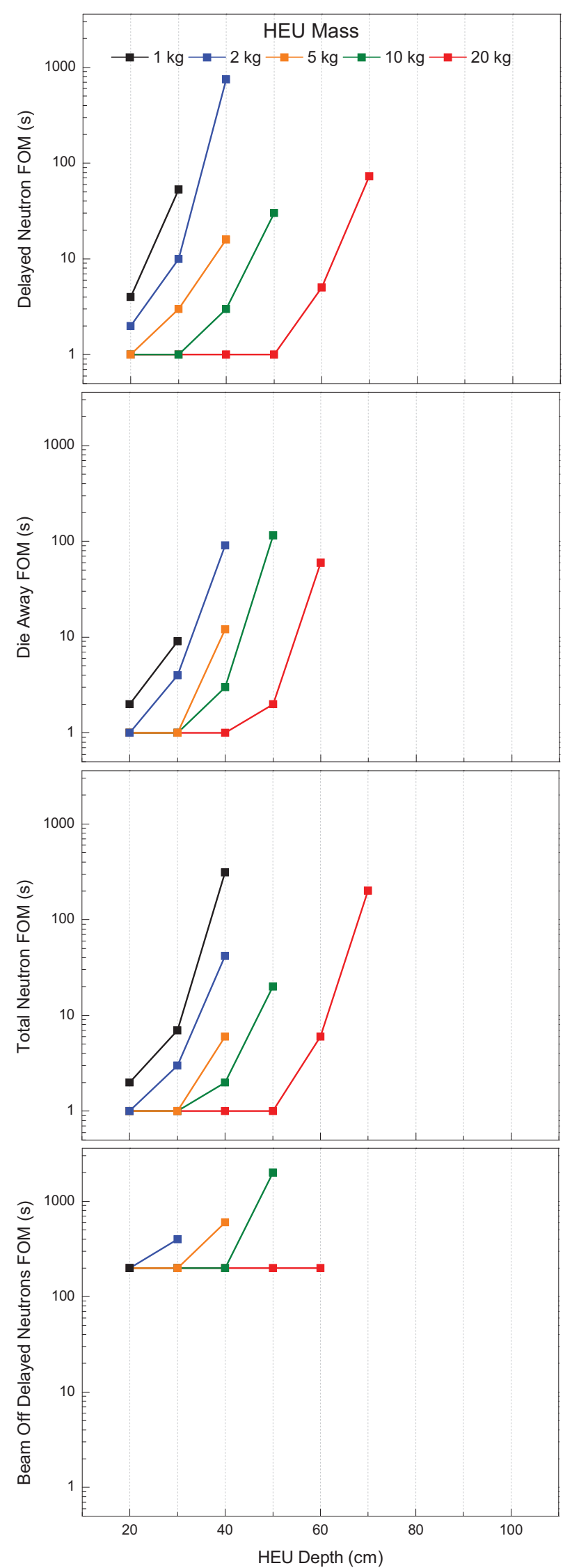

Fig. 4 FOM values for the cement bulk shield with $5 \mathrm{~cm}$ of stainless steel near shielding. Values assume $1 \%$ false alarm and $1 \%$ miss rates, with a background count rate of 300 counts per minute per detector; DT10 ${ }^{8}$.
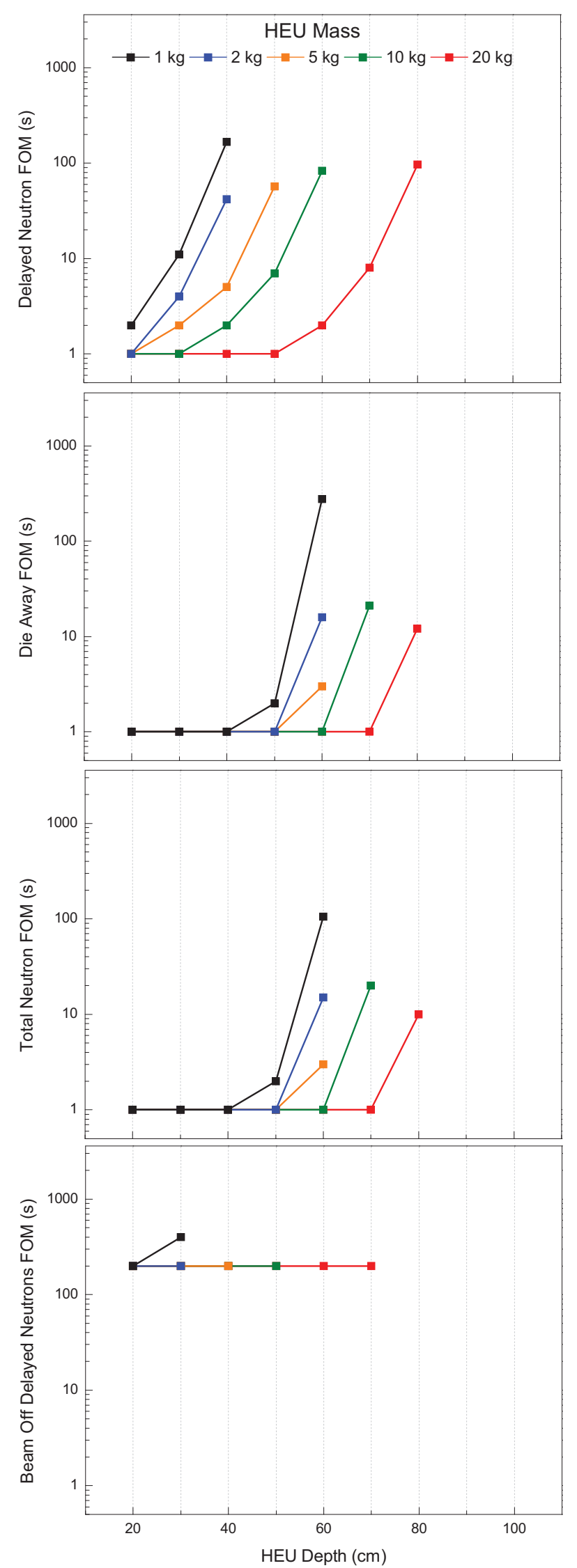

Fig. 5 FOM values for the cement bulk shield with $5 \mathrm{~cm}$ of $\mathrm{Pb}$ near shielding. Values assume $1 \%$ false alarm and $1 \%$ miss rates, with a background count rate of 300 counts per minute per detector; DT10 ${ }^{8}$. 
INL-CON-12-25806
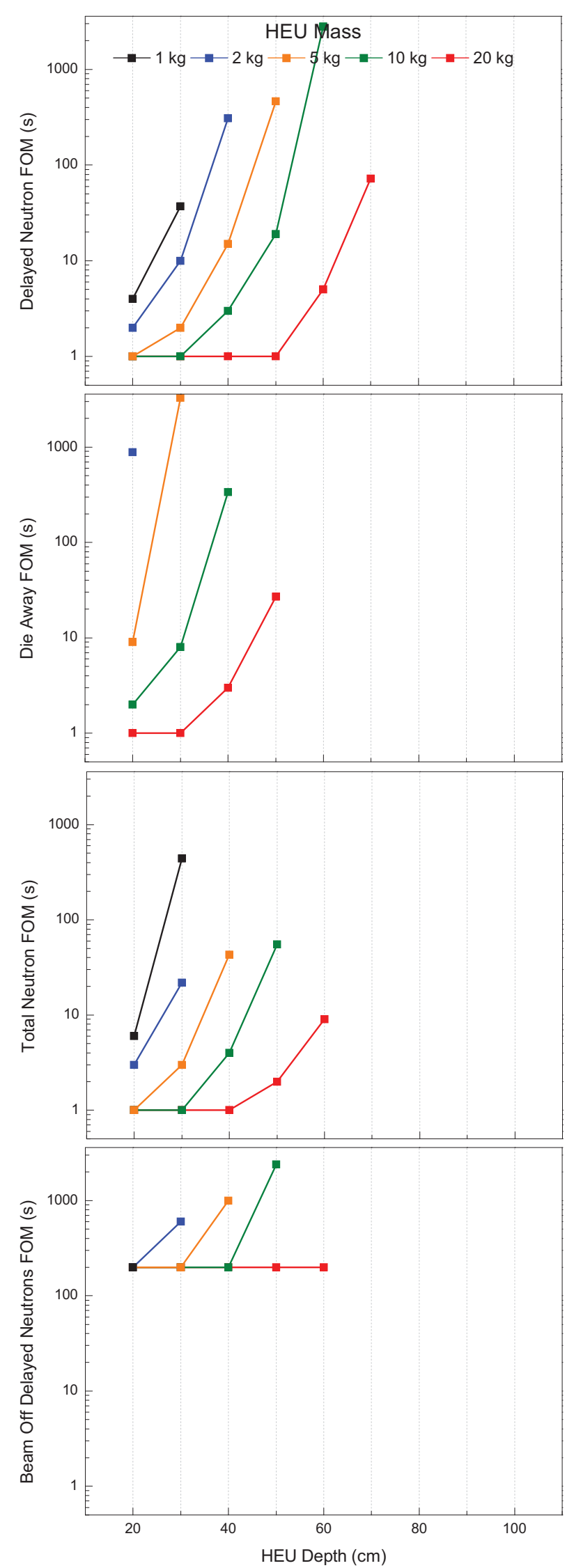

Fig. 6 FOM values for the cement bulk shield with $1 \mathrm{~mm}$ of $\mathrm{Cd}$ near shielding. Values assume $1 \%$ false alarm and $1 \%$ miss rates, with a background count rate of 300 counts per minute per detector; DT10 ${ }^{8}$.
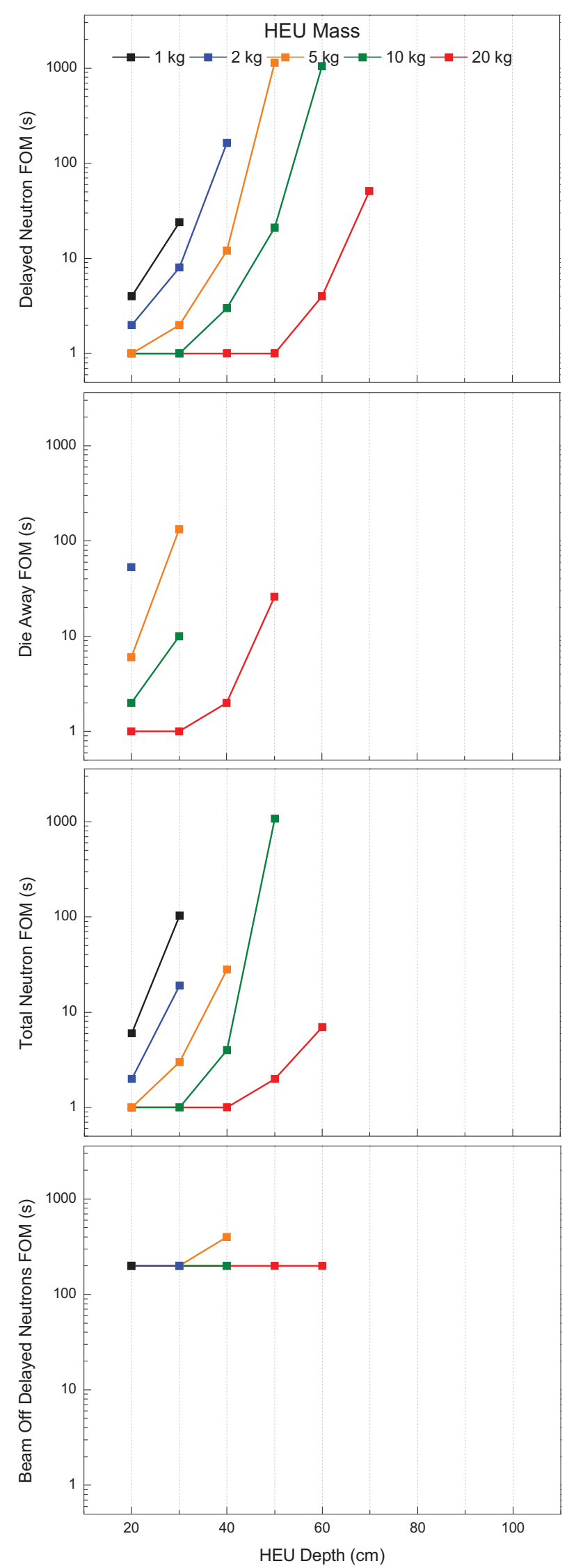

Fig. 7 FOM values for the cement bulk shield with $1 \mathrm{~mm} \mathrm{Cd}$ and $5 \mathrm{~cm} \mathrm{~Pb}$ near shielding. Values assume 1\% false alarm and $1 \%$ miss rates, with a background count rate of 300 counts per minute per detector; DT $10^{8}$. 


\section{B. No Shielding - Air}

The following five tables (Table I through Table V) present results for the FOM analysis, in a modified format, of detecting HEU without a bulk shield. In these tables green indicates the material is detected with a FN probability $<0.1 \%$ for FP probabilities of $\leq 31.7 \%(1 \sigma), \leq 4.6 \%(2 \sigma)$, and $\leq$ $0.3 \%(3 \sigma)$, for two background conditions, either $0.5 \mathrm{~s}^{-1}$ or 5 $\mathrm{s}^{-1}$. Yellow indicates the FN rate is $>0.1 \%$ but $\leq 50 \%$. Red indicates the FN rate is $>50 \%$. Results are presented after 1 hour, for cases with the HEU centered $0.2 \mathrm{~m}, 0.5 \mathrm{~m}$, or $1 \mathrm{~m}$ from the outside surface. All of the near-shield cases are presented including no near shield and near shields of $5 \mathrm{~cm}$ of stainless steel, $5 \mathrm{~cm}$ of lead, $1 \mathrm{~mm}$ of cadmium, or a combined shield with the HEU surrounded with $1 \mathrm{~mm}$ of cadmium, and then the cadmium surrounded with $5 \mathrm{~cm}$ of lead.

This scenario is the easiest case for detection. The lack of nearby reflector/moderator materials eliminates the die-away signature for the smaller masses (some deviation can be detected in the detector recovery due to fast-fission die-away for the higher-mass cases) but the pure induced fission from direct irradiation with the interrogation-source neutrons yields a readily measurable signature. Measurement of $\beta$-delayed neutrons at equilibrium versus while decaying, i.e., after the beam has been turned off, is always a better measurement to perform. After the beam has been turned off the $\beta$-delayed gamma-ray signature, shown here for DD irradiation rather than DT irradiation, isn't quite as useful as the beam-off $\beta$ delayed neutron signature since the values reported here for $\beta$ delayed neutrons are with a DT source, not a DD source.

TABLE I 1 -HouR $/$ AIR/DT10 8 /PULSING/ $\beta$-DELAYED NeUtRONS.

\begin{tabular}{|c|c|c|c|c|c|c|c|c|c|c|c|c|c|c|c|c|c|c|}
\hline \multirow{3}{*}{$\begin{array}{c}\text { Near } \\
\text { Shield } \\
\text { Case, } \\
\text { mass/ } \\
\text { shield }\end{array}$} & \multicolumn{9}{|c|}{$B=0.5 s^{-1}$} & \multicolumn{9}{|c|}{$B=5 \mathrm{~s}^{-1}$} \\
\hline & \multicolumn{3}{|c|}{$\mathbf{F P}=1 \sigma$} & \multicolumn{3}{|c|}{$\mathbf{F P}=2 \sigma$} & \multicolumn{3}{|c|}{$\mathbf{F P}=\mathbf{3} \sigma$} & \multicolumn{3}{|c|}{$\mathbf{F P}=1 \sigma$} & \multicolumn{3}{|c|}{$\mathbf{F P}=2 \sigma$} & \multicolumn{3}{|c|}{$F P=3 \sigma$} \\
\hline & \begin{tabular}{c}
$\Xi$ \\
\multirow{3}{0}{}
\end{tabular} & 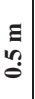 & $\Xi$ & 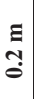 & $\begin{array}{l}\text { घ } \\
\text { 'n? }\end{array}$ & $\Xi$ & \begin{tabular}{l}
$\Xi$ \\
\multirow{S}{\delta}{}
\end{tabular} & 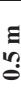 & $\Xi$ & 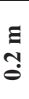 & 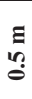 & $\Xi$ & $\begin{array}{l}\Xi \\
\Xi \\
\tilde{o}\end{array}$ & 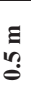 & $\Xi$ & 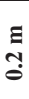 & 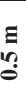 & $\Xi$ \\
\hline 1 & & & & & & & & & & & & & & & & & & \\
\hline $1 / \mathrm{SS}$ & & & & & & & & & & & & & & & & & & \\
\hline $1 / \mathrm{Pb}$ & & & & & & & & & & & & & & & & & & \\
\hline $1 / \mathrm{Cd}$ & & & & & & & & & & & & & & & & & & \\
\hline $1 / \mathrm{Pb}-\mathrm{Cd}$ & & & & & & & & & & & & & & & & & & \\
\hline 2 & & & & & & & & & & & & & & & & & & \\
\hline $2 / \mathrm{SS}$ & & & & & & & & & & & & & & & & & & \\
\hline $2 / \mathrm{Pb}$ & & & & & & & & & & & & & & & & & & \\
\hline $2 / \mathrm{Cd}$ & & & & & & & & & & & & & & & & & & \\
\hline $2 / \mathrm{Pb}-\mathrm{Cd}$ & & & & & & & & & & & & & & & & & & \\
\hline 5 & & & & & & & & & & & & & & & & & & \\
\hline $5 / \mathrm{SS}$ & & & & & & & & & & & & & & & & & & \\
\hline $5 / \mathrm{Pb}$ & & & & & & & & & & & & & & & & & & \\
\hline $5 / \mathrm{Cd}$ & & & & & & & & & & & & & & & & & & \\
\hline $5 / \mathrm{Pb}-\mathrm{Cd}$ & & & & & & & & & & & & & & & & & & \\
\hline 10 & & & & & & & & & & & & & & & & & & \\
\hline $10 / \mathrm{SS}$ & & & & & & & & & & & & & & & & & & \\
\hline $10 / \mathrm{Pb}$ & & & & & & & & & & & & & & & & & & \\
\hline $10 / \mathrm{Cd}$ & & & & & & & & & & & & & & & & & & \\
\hline $10 / \mathrm{Pb}-\mathrm{Cd}$ & & & & & & & & & & & & & & & & & & \\
\hline 20 & & & & & & & & & & & & & & & & & & \\
\hline $20 / \mathrm{SS}$ & & & & & & & & & & & & & & & & & & \\
\hline $20 / \mathrm{Pb}$ & & & & & & & & & & & & & & & & & & \\
\hline $20 / \mathrm{Cd}$ & & & & & & & & & & & & & & & & & & \\
\hline $20 / \mathrm{Pb}-\mathrm{Cd}$ & & & & & & & & & & & & & & & & & & \\
\hline
\end{tabular}

TABLE II 1-Hour/AIR/DT10 $0^{8} /$ PULSING/DIE-AWAY NEUTRONS.

\begin{tabular}{|c|c|c|c|c|c|c|c|c|c|c|c|c|c|c|c|c|c|c|c|}
\hline \multirow{3}{*}{$\begin{array}{l}\text { Near } \\
\text { Shield } \\
\text { Case, } \\
\text { mass/ } \\
\text { shield }\end{array}$} & \multicolumn{10}{|c|}{$B=0.5 \mathrm{~s}^{-1}$} & \multicolumn{9}{|c|}{$B=5 s^{-1}$} \\
\hline & \multicolumn{3}{|c|}{$\mathbf{F P}=1 \sigma$} & \multicolumn{3}{|c|}{$\mathbf{F P}=2 \sigma$} & \multicolumn{4}{|c|}{$F P=3 \sigma$} & \multicolumn{3}{|c|}{$\mathbf{F P}=1 \sigma$} & \multicolumn{3}{|c|}{$\mathbf{F P}=\mathbf{2} \sigma$} & \multicolumn{3}{|c|}{$\mathbf{F P}=3 \sigma$} \\
\hline & $\underset{\Xi}{\stackrel{\Xi}{\Xi}}$ & 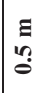 & $\Xi$ & $\begin{array}{l}\Xi \\
\stackrel{\Xi}{\varrho}\end{array}$ & 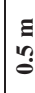 & $\Xi$ & & & $\frac{8}{8}$ & $\Xi$ & \begin{tabular}{c}
$\Xi$ \\
\multirow{\Xi}{\Xi}{}
\end{tabular} & 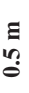 & $\Xi$ & $\begin{array}{l}\Xi \\
\text { a }\end{array}$ & & $\Xi$ & & हn: & $\Xi$ \\
\hline 1 & & & & & & & & & & & & & & & & & & & \\
\hline $1 / \mathrm{SS}$ & & & & & & & & & & & & & & & & & & & \\
\hline $1 / \mathrm{Pb}$ & & & & & & & & & & & & & & & & & & & \\
\hline $1 / \mathrm{Cd}$ & & & & & & & & & & & & & & & & & & & \\
\hline $1 / \mathrm{Pb}-\mathrm{Cd}$ & & & & & & & & & & & & & & & & & & & \\
\hline 2 & & & & & & & & & & & & & & & & & & & \\
\hline $2 / \mathrm{SS}$ & & & & & & & & & & & & & & & & & & & \\
\hline $2 / \mathrm{Pb}$ & & & & & & & & & & & & & & & & & & & \\
\hline $2 / \mathrm{Cd}$ & & & & & & & & & & & & & & & & & & & \\
\hline $2 / \mathrm{Pb}-\mathrm{Cd}$ & & & & & & & & & & & & & & & & & & & \\
\hline 5 & & & & & & & & & & & & & & & & & & & \\
\hline $5 / \mathrm{SS}$ & & & & & & & & & & & & & & & & & & & \\
\hline $5 / \mathrm{Pb}$ & & & & & & & & & & & & & & & & & & & \\
\hline $5 / \mathrm{Cd}$ & & & & & & & & & & & & & & & & & & & \\
\hline $5 / \mathrm{Pb}-\mathrm{Cd}$ & & & & & & & & & & & & & & & & & & & \\
\hline 10 & & & & & & & & & & & & & & & & & & & \\
\hline $10 / \mathrm{SS}$ & & & & & & & & & & & & & & & & & & & \\
\hline $10 / \mathrm{Pb}$ & & & & & & & & & & & & & & & & & & & \\
\hline $10 / \mathrm{Cd}$ & & & & & & & & & & & & & & & & & & & \\
\hline $10 / \mathrm{Pb}-\mathrm{Cd}$ & & & & & & & & & & & & & & & & & & & \\
\hline 20 & & & & & & & & & & & & & & & & & & & \\
\hline $20 / \mathrm{SS}$ & & & & & & & & & & & & & & & & & & & \\
\hline $20 / \mathrm{Pb}$ & & & & & & & & & & & & & & & & & & & \\
\hline $20 / \mathrm{Cd}$ & & & & & & & & & & & & & & & & & & & \\
\hline $20 / \mathrm{Pb}-\mathrm{Cd}$ & & & & & & & & & & & & & & & & & & & \\
\hline
\end{tabular}

TABLE III 1 -Hour/Air/DT10 8 /Pulsing/Total Neutrons.

\begin{tabular}{|c|c|c|c|c|c|c|c|c|c|c|c|c|c|c|c|c|c|c|c|c|}
\hline \multirow{3}{*}{$\begin{array}{l}\text { Near } \\
\text { Shield } \\
\text { Case, } \\
\text { mass/ } \\
\text { shield }\end{array}$} & \multicolumn{10}{|c|}{$B=0.5 s^{-1}$} & \multicolumn{10}{|c|}{$B=5 s^{-1}$} \\
\hline & \multicolumn{3}{|c|}{$\mathbf{F P}=1 \sigma$} & \multicolumn{4}{|c|}{$\mathbf{F P}=2 \sigma$} & \multicolumn{3}{|c|}{$\mathbf{F P}=3 \sigma$} & \multicolumn{4}{|c|}{$F P=1 \sigma$} & \multicolumn{3}{|c|}{$\mathbf{F P}=2 \sigma$} & \multicolumn{3}{|c|}{$\mathbf{F P}=3 \sigma$} \\
\hline & $\begin{array}{l}\Xi \\
\text { } \\
\text { }\end{array}$ & 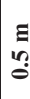 & 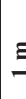 & & & & & $\begin{array}{l} \pm \\
\end{array}$ & 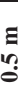 & 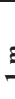 & & 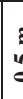 & & & $\begin{array}{c}\mathbb{E} \\
\text { ș }\end{array}$ & \begin{tabular}{c}
$\Xi$ \\
$\vdots$ \\
\hdashline \\
\hdashline
\end{tabular} & $\Xi$ & & & \\
\hline 1 & & & & & & & & & & & & & & & & & & & & \\
\hline $1 / \mathrm{SS}$ & & & & & & & & & & & & & & & & & & & & \\
\hline $1 / \mathrm{Pb}$ & & & & & & & & & & & & & & & & & & & & \\
\hline $1 / \mathrm{Cd}$ & & & & & & & & & & & & & & & & & & & & \\
\hline $1 / \mathrm{Pb}-\mathrm{Cd}$ & & & & & & & & & & & & & & & & & & & & \\
\hline 2 & & & & & & & & & & & & & & & & & & & & \\
\hline $2 / \mathrm{SS}$ & & & & & & & & & & & & & & & & & & & & \\
\hline $2 / \mathrm{Pb}$ & & & & & & & & & & & & & & & & & & & & \\
\hline $2 / \mathrm{Cd}$ & & & & & & & & & & & & & & & & & & & & \\
\hline $2 / \mathrm{Pb}-\mathrm{Cd}$ & & & & & & & & & & & & & & & & & & & & \\
\hline 5 & & & & & & & & & & & & & & & & & & & & \\
\hline $5 / \mathrm{SS}$ & & & & & & & & & & & & & & & & & & & & \\
\hline $5 / \mathrm{Pb}$ & & & & & & & & & & & & & & & & & & & & \\
\hline $5 / \mathrm{Cd}$ & & & & & & & & & & & & & & & & & & & & \\
\hline $5 / \mathrm{Pb}-\mathrm{Cd}$ & & & & & & & & & & & & & & & & & & & & \\
\hline 10 & & & & & & & & & & & & & & & & & & & & \\
\hline $10 / \mathrm{SS}$ & & & & & & & & & & & & & & & & & & & & \\
\hline $10 / \mathrm{Pb}$ & & & & & & & & & & & & & & & & & & & & \\
\hline $10 / \mathrm{Cd}$ & & & & & & & & & & & & & & & & & & & & \\
\hline $10 / \mathrm{Pb}-\mathrm{Cd}$ & & & & & & & & & & & & & & & & & & & & \\
\hline 20 & & & & & & & & & & & & & & & & & & & & \\
\hline $20 / \mathrm{SS}$ & & & & & & & & & & & & & & & & & & & & \\
\hline $20 / \mathrm{Pb}$ & & & & & & & & & & & & & & & & & & & & \\
\hline $20 / \mathrm{Cd}$ & & & & & & & & & & & & & & & & & & & & \\
\hline $20 / \mathrm{Pb}-\mathrm{Cd}$ & & & & & & & & & & & & & & & & & & & & \\
\hline
\end{tabular}


TABLE IV 1-Hour/AIR/DT10\%的AM-OFF/ $\beta$-DELAYED NEUTRONS.

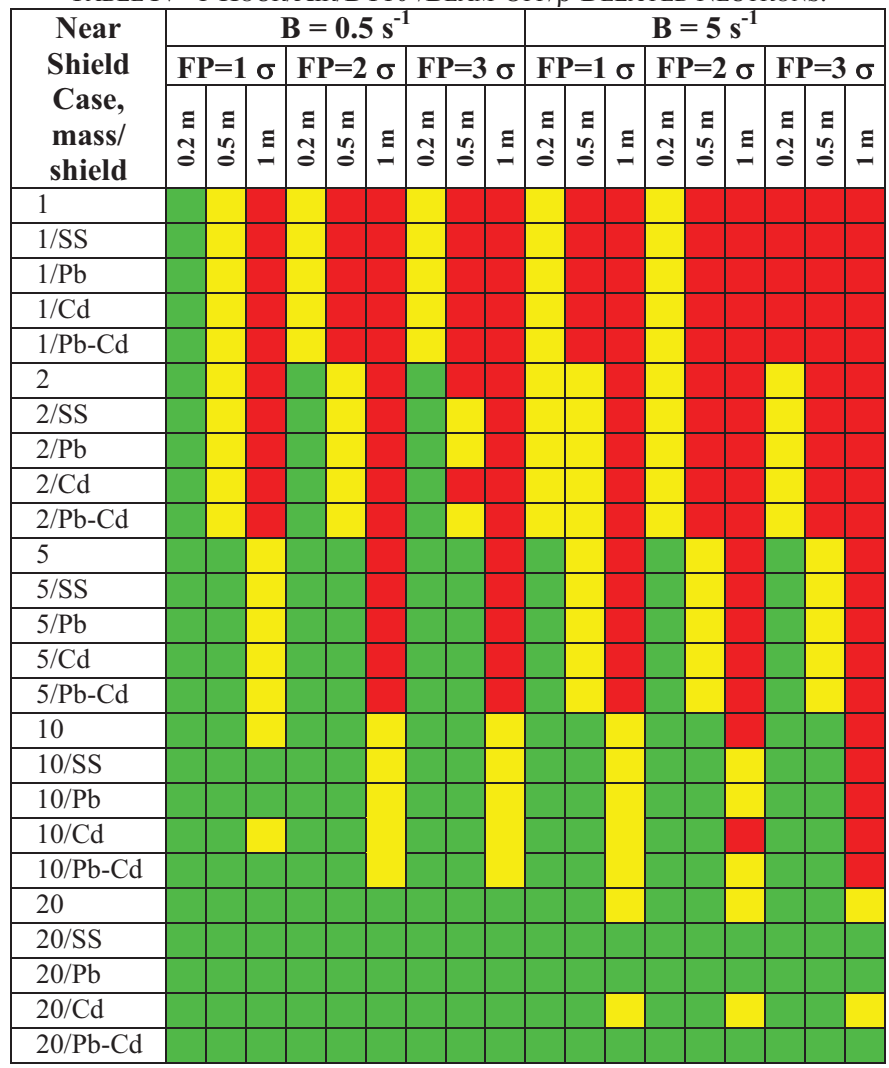

TABLE V 1-HOUR/AIR/DD10 $0^{8} /$ BEAM-OFF/ $\beta$-DELAYED GAMMA RAYS

\begin{tabular}{|c|c|c|c|c|c|c|c|c|c|c|c|c|c|c|c|c|c|c|c|}
\hline \multirow{3}{*}{$\begin{array}{c}\text { Near } \\
\text { Shield } \\
\text { Case, } \\
\text { mass/ } \\
\text { shield }\end{array}$} & \multicolumn{9}{|c|}{$B=0.5 \mathrm{~s}^{-1}$} & \multicolumn{10}{|c|}{$B=5 s^{-1}$} \\
\hline & \multicolumn{3}{|c|}{$\mathbf{F P}=1 \sigma$} & \multicolumn{3}{|c|}{$\mathbf{F P}=2 \sigma$} & \multicolumn{4}{|c|}{$\mathbf{F P}=3 \sigma$} & \multicolumn{3}{|c|}{$\mathbf{F P}=1 \sigma$} & \multicolumn{3}{|c|}{$\mathbf{F P}=2 \sigma$} & \multicolumn{3}{|c|}{$\mathbf{F P}=\mathbf{3} \sigma$} \\
\hline & $\begin{array}{c}\Xi \\
\Xi \\
\Xi \\
0\end{array}$ & \begin{tabular}{c}
$\Xi$ \\
$\vdots$ \\
$ٌ$ \\
\hdashline
\end{tabular} & $\Xi$ & 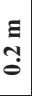 & $\begin{array}{l}\Xi \\
0 \\
0\end{array}$ & $\Xi$ & 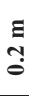 & 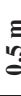 & & & $\begin{array}{l}E \\
y \\
\end{array}$ & $\begin{array}{c}\Xi \\
\vdots \\
\vdots \\
\vdots\end{array}$ & $\Xi$ & 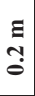 & $\begin{array}{c}\Xi \\
n \\
n \\
0\end{array}$ & $\Xi$ & $\begin{array}{l}\Xi \\
\text { İ }\end{array}$ & & $\begin{array}{lll}- & \\
-1\end{array}$ \\
\hline 1 & & & & & & & & & & & & & & & & & & & \\
\hline $1 / \mathrm{SS}$ & & & & & & & & & & & & & & & & & & & \\
\hline $1 / \mathrm{Pb}$ & & & & & & & & & & & & & & & & & & & \\
\hline $1 / \mathrm{Cd}$ & & & & & & & & & & & & & & & & & & & \\
\hline $1 / \mathrm{Pb}-\mathrm{Cd}$ & & & & & & & & & & & & & & & & & & & \\
\hline 2 & & & & & & & & & & & & & & & & & & & \\
\hline $2 / \mathrm{SS}$ & & & & & & & & & & & & & & & & & & & \\
\hline $2 / \mathrm{Pb}$ & & & & & & & & & & & & & & & & & & & \\
\hline $2 / \mathrm{Cd}$ & & & & & & & & & & & & & & & & & & & \\
\hline $2 / \mathrm{Pb}-\mathrm{Cd}$ & & & & & & & & & & & & & & & & & & & \\
\hline 5 & & & & & & & & & & & & & & & & & & & \\
\hline $5 / \mathrm{SS}$ & & & & & & & & & & & & & & & & & & & \\
\hline $5 / \mathrm{Pb}$ & & & & & & & & & & & & & & & & & & & \\
\hline $5 / \mathrm{Cd}$ & & & & & & & & & & & & & & & & & & & \\
\hline $5 / \mathrm{Pb}-\mathrm{Cd}$ & & & & & & & & & & & & & & & & & & & \\
\hline 10 & & & & & & & & & & & & & & & & & & & \\
\hline $10 / \mathrm{SS}$ & & & & & & & & & & & & & & & & & & & \\
\hline $10 / \mathrm{Pb}$ & & & & & & & & & & & & & & & & & & & \\
\hline $10 / \mathrm{Cd}$ & & & & & & & & & & & & & & & & & & & \\
\hline $10 / \mathrm{Pb}-\mathrm{Cd}$ & & & & & & & & & & & & & & & & & & & \\
\hline 20 & & & & & & & & & & & & & & & & & & & \\
\hline $20 / \mathrm{SS}$ & & & & & & & & & & & & & & & & & & & \\
\hline $20 / \mathrm{Pb}$ & & & & & & & & & & & & & & & & & & & \\
\hline $20 / \mathrm{Cd}$ & & & & & & & & & & & & & & & & & & & \\
\hline $20 / \mathrm{Pb}-\mathrm{Cd}$ & & & & & & & & & & & & & & & & & & & \\
\hline
\end{tabular}

\section{Polyethylene Bulk Shielding}

The following five tables (Table VI through Table X) present data similar to the previous section but for a polyethylene bulk shield. Bulk hydrogenous shielding is generally considered one of the most difficult types of shielding for ANI to work with, and the results here confirm that supposition. The results suggest that the combined product of neutron attenuation for the interrogation source neutrons reaching the HEU plus attenuation of the neutronbased signatures as they exit through this shielding significantly reduces the intensity of the signatures to be measured. This contrast is perhaps most strongly seen by comparing Table I, where the $\beta$-delayed neutron signatures effectively detects the HEU under nearly every scenario, and Table VI where successful detection seems to lie between 0.2 $\mathrm{m}$ and $0.5 \mathrm{~m}$ and never reaches the full $1-\mathrm{m}$ depth.

For cases without steel or lead, the DD $10^{8}$ beam-off $\beta$ delayed gamma-ray signature shown in Table $\mathrm{X}$ is more capable for detection than the DT10 ${ }^{8}$ beam-off $\beta$-delayed neutron signature of Table IX. This is due to the higher yield of $\beta$-delayed gamma-rays than neutrons and the fact that the fission-inducing neutron septa are nearly equivalent due the excessive moderation in the polyethylene, regardless of whether the DD or DT spectra are used for interrogation. This is in contrast with the above comparisons for no bulk shielding. Without the polyethylene moderator, the higher fission cross-section for $14.1 \mathrm{MeV}$ neutrons vs. 2.5 neutrons dominates this effect. For the bulk polyethylene shielding this effect is negated.

Table VI 1-Hour/Poly./DT10 ${ }^{8} /$ Pulsing/ $\beta$-Delayed Neutrons.

\begin{tabular}{|c|c|c|c|c|c|c|c|c|c|c|c|c|c|c|c|c|c|c|c|}
\hline \multirow{3}{*}{$\begin{array}{l}\text { Near } \\
\text { Shield } \\
\text { Case, } \\
\text { mass/ } \\
\text { shield }\end{array}$} & \multicolumn{10}{|c|}{$B=0.5 \mathrm{~s}^{-1}$} & \multicolumn{9}{|c|}{$B=5 s^{-1}$} \\
\hline & \multicolumn{3}{|c|}{$\mathbf{F P}=1 \sigma$} & \multicolumn{3}{|c|}{$\mathbf{F P}=2 \sigma$} & \multicolumn{4}{|c|}{$\mathbf{F P}=3 \sigma$} & \multicolumn{3}{|c|}{$\mathbf{F P}=1 \sigma$} & \multicolumn{3}{|c|}{$\mathbf{F P}=2 \sigma$} & \multicolumn{3}{|c|}{$\mathbf{F P}=3 \sigma$} \\
\hline & 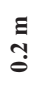 & 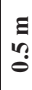 & $\Xi$ & 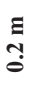 & $\begin{array}{l}\Xi \\
\text { no }\end{array}$ & $\Xi$ & 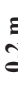 & & & $\Xi$ & $\begin{array}{l}\Xi \\
\text { ֻ }\end{array}$ & $\begin{array}{c}\Xi \\
\vdots \\
0\end{array}$ & $\Xi$ & \begin{tabular}{c}
$\Xi$ \\
\multirow{g}{*}{}
\end{tabular} & & $\Xi$ & & 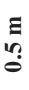 & \\
\hline 1 & & & & & & & & & & & & & & & & & & & \\
\hline $1 / \mathrm{SS}$ & & & & & & & & & & & & & & & & & & & \\
\hline $1 / \mathrm{Pb}$ & & & & & & & & & & & & & & & & & & & \\
\hline $1 / \mathrm{Cd}$ & & & & & & & & & & & & & & & & & & & \\
\hline $1 / \mathrm{Pb}-\mathrm{Cd}$ & & & & & & & & & & & & & & & & & & & \\
\hline 2 & & & & & & & & & & & & & & & & & & & \\
\hline $2 / \mathrm{SS}$ & & & & & & & & & & & & & & & & & & & \\
\hline $2 / \mathrm{Pb}$ & & & & & & & & & & & & & & & & & & & \\
\hline $2 / \mathrm{Cd}$ & & & & & & & & & & & & & & & & & & & \\
\hline $2 / \mathrm{Pb}-\mathrm{Cd}$ & & & & & & & & & & & & & & & & & & & \\
\hline 5 & & & & & & & & & & & & & & & & & & & \\
\hline $5 / \mathrm{SS}$ & & & & & & & & & & & & & & & & & & & \\
\hline $5 / \mathrm{Pb}$ & & & & & & & & & & & & & & & & & & & \\
\hline $5 / \mathrm{Cd}$ & & & & & & & & & & & & & & & & & & & \\
\hline $5 / \mathrm{Pb}-\mathrm{Cd}$ & & & & & & & & & & & & & & & & & & & \\
\hline 10 & & & & & & & & & & & & & & & & & & & \\
\hline $10 / \mathrm{SS}$ & & & & & & & & & & & & & & & & & & & \\
\hline $10 / \mathrm{Pb}$ & & & & & & & & & & & & & & & & & & & \\
\hline $10 / \mathrm{Cd}$ & & & & & & & & & & & & & & & & & & & \\
\hline $10 / \mathrm{Pb}-\mathrm{Cd}$ & & & & & & & & & & & & & & & & & & & \\
\hline 20 & & & & & & & & & & & & & & & & & & & \\
\hline $20 / \mathrm{SS}$ & & & & & & & & & & & & & & & & & & & \\
\hline $20 / \mathrm{Pb}$ & & & & & & & & & & & & & & & & & & & \\
\hline $20 / \mathrm{Cd}$ & & & & & & & & & & & & & & & & & & & \\
\hline $20 / \mathrm{Pb}-\mathrm{Cd}$ & & & & & & & & & & & & & & & & & & & \\
\hline
\end{tabular}


TABLE VII 1-Hour/Poly./DT10 8 /PUlsing/Die-AwAY NeUtRONS.

\begin{tabular}{|c|c|c|c|c|c|c|c|c|c|c|c|c|c|c|c|c|c|c|}
\hline \multirow{3}{*}{$\begin{array}{c}\text { Near } \\
\text { Shield } \\
\text { Case, } \\
\text { mass/ } \\
\text { shield }\end{array}$} & \multicolumn{9}{|c|}{$B=0.5 s^{-1}$} & \multicolumn{9}{|c|}{$B=5 s^{-1}$} \\
\hline & \multicolumn{3}{|c|}{$\mathbf{F P}=1 \sigma$} & \multicolumn{3}{|c|}{$\mathbf{F P}=2 \sigma$} & \multicolumn{3}{|c|}{$\mathbf{F P}=3 \sigma$} & \multicolumn{3}{|c|}{$F P=1 \sigma$} & \multicolumn{3}{|c|}{$\mathbf{F P}=2 \sigma$} & \multicolumn{3}{|c|}{$\mathrm{FP}=3 \sigma$} \\
\hline & $\begin{array}{c}\Xi \\
\dddot{\Xi} \\
e\end{array}$ & \begin{tabular}{c}
$\Xi$ \\
$n$ \\
\hdashline \\
0
\end{tabular} & $\Xi$ & 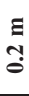 & 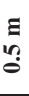 & $\Xi$ & $\begin{array}{l}\mathbb{E} \\
\text { İ }\end{array}$ & 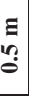 & $\Xi$ & $\begin{array}{l}\mathbb{\Xi} \\
\stackrel{9}{\sigma}\end{array}$ & 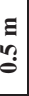 & $\exists$ & $\begin{array}{c}\Xi \\
\stackrel{\Xi}{ } \\
\stackrel{5}{0}\end{array}$ & 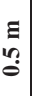 & $\Xi$ & \begin{tabular}{l}
$\Xi$ \\
\multirow{3}{*}{}
\end{tabular} & 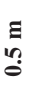 & $\Xi$ \\
\hline 1 & & & & & & & & & & & & & & & & & & \\
\hline $1 / \mathrm{SS}$ & & & & & & & & & & & & & & & & & & \\
\hline $1 / \mathrm{Pb}$ & & & & & & & & & & & & & & & & & & \\
\hline $1 / \mathrm{Cd}$ & & & & & & & & & & & & & & & & & & \\
\hline $1 / \mathrm{Pb}-\mathrm{Cd}$ & & & & & & & & & & & & & & & & & & \\
\hline 2 & & & & & & & & & & & & & & & & & & \\
\hline $2 / \mathrm{SS}$ & & & & & & & & & & & & & & & & & & \\
\hline $2 / \mathrm{Pb}$ & & & & & & & & & & & & & & & & & & \\
\hline $2 / \mathrm{Cd}$ & & & & & & & & & & & & & & & & & & \\
\hline $2 / \mathrm{Pb}-\mathrm{Cd}$ & & & & & & & & & & & & & & & & & & \\
\hline 5 & & & & & & & & & & & & & & & & & & \\
\hline $5 / \mathrm{SS}$ & & & & & & & & & & & & & & & & & & \\
\hline $5 / \mathrm{Pb}$ & & & & & & & & & & & & & & & & & & \\
\hline $5 / \mathrm{Cd}$ & & & & & & & & & & & & & & & & & & \\
\hline $5 / \mathrm{Pb}-\mathrm{Cd}$ & & & & & & & & & & & & & & & & & & \\
\hline 10 & & & & & & & & & & & & & & & & & & \\
\hline $10 / \mathrm{SS}$ & & & & & & & & & & & & & & & & & & \\
\hline $10 / \mathrm{Pb}$ & & & & & & & & & & & & & & & & & & \\
\hline $10 / \mathrm{Cd}$ & & & & & & & & & & & & & & & & & & \\
\hline $10 / \mathrm{Pb}-\mathrm{Cd}$ & & & & & & & & & & & & & & & & & & \\
\hline 20 & & & & & & & & & & & & & & & & & & \\
\hline $20 / \mathrm{SS}$ & & & & & & & & & & & & & & & & & & \\
\hline $20 / \mathrm{Pb}$ & & & & & & & & & & & & & & & & & & \\
\hline $20 / \mathrm{Cd}$ & & & & & & & & & & & & & & & & & & \\
\hline $20 / \mathrm{Pb}-\mathrm{Cd}$ & & & & & & & & & & & & & & & & & & \\
\hline
\end{tabular}

TABle VIII 1-Hour/Poly./DT10 10 Pulsing/Total Neutrons.

\begin{tabular}{|c|c|c|c|c|c|c|c|c|c|c|c|c|c|c|c|c|c|c|}
\hline \multirow{3}{*}{$\begin{array}{c}\text { Near } \\
\text { Shield } \\
\text { Case, } \\
\text { mass/ } \\
\text { shield }\end{array}$} & \multicolumn{9}{|c|}{$B=0.5 s^{-1}$} & \multicolumn{9}{|c|}{$B=5 s^{-1}$} \\
\hline & \multicolumn{3}{|c|}{$\mathrm{FP}=1 \sigma$} & \multicolumn{3}{|c|}{$\mathbf{F P}=2 \sigma$} & \multicolumn{3}{|c|}{$\mathbf{F P}=3 \sigma$} & \multicolumn{3}{|c|}{$F P=1 \sigma$} & \multicolumn{3}{|c|}{$\mathbf{F P}=2 \sigma$} & \multicolumn{3}{|c|}{$\mathbf{F P}=3 \sigma$} \\
\hline & 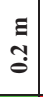 & 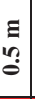 & $\Xi$ & 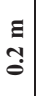 & $\begin{array}{c}\mathbb{B} \\
\text { in }\end{array}$ & $\Xi$ & $\begin{array}{l}\Xi \\
\stackrel{\Xi}{\text { s. }}\end{array}$ & $\begin{array}{l}\Xi \\
n \\
\Leftrightarrow\end{array}$ & $\Xi$ & 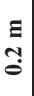 & $\begin{array}{c}\Xi \\
\vdots \\
n \\
0\end{array}$ & $\Xi$ & $\begin{array}{c}\Xi \\
\mathfrak{s} \\
\Xi\end{array}$ & 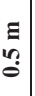 & $\Xi$ & & 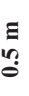 & $\Xi$ \\
\hline 1 & & & & & & & & & & & & & & & & & & \\
\hline $1 / \mathrm{SS}$ & & & & & & & & & & & & & & & & & & \\
\hline $1 / \mathrm{Pb}$ & & & & & & & & & & & & & & & & & & \\
\hline $1 / \mathrm{Cd}$ & & & & & & & & & & & & & & & & & & \\
\hline $1 / \mathrm{Pb}-\mathrm{Cd}$ & & & & & & & & & & & & & & & & & & \\
\hline 2 & & & & & & & & & & & & & & & & & & \\
\hline $2 / \mathrm{SS}$ & & & & & & & & & & & & & & & & & & \\
\hline $2 / \mathrm{Pb}$ & & & & & & & & & & & & & & & & & & \\
\hline $2 / \mathrm{Cd}$ & & & & & & & & & & & & & & & & & & \\
\hline $2 / \mathrm{Pb}-\mathrm{Cd}$ & & & & & & & & & & & & & & & & & & \\
\hline 5 & & & & & & & & & & & & & & & & & & \\
\hline $5 / \mathrm{SS}$ & & & & & & & & & & & & & & & & & & \\
\hline $5 / \mathrm{Pb}$ & & & & & & & & & & & & & & & & & & \\
\hline $5 / \mathrm{Cd}$ & & & & & & & & & & & & & & & & & & \\
\hline $5 / \mathrm{Pb}-\mathrm{Cd}$ & & & & & & & & & & & & & & & & & & \\
\hline 10 & & & & & & & & & & & & & & & & & & \\
\hline $10 / \mathrm{SS}$ & & & & & & & & & & & & & & & & & & \\
\hline $10 / \mathrm{Pb}$ & & & & & & & & & & & & & & & & & & \\
\hline $10 / \mathrm{Cd}$ & & & & & & & & & & & & & & & & & & \\
\hline $10 / \mathrm{Pb}-\mathrm{Cd}$ & & & & & & & & & & & & & & & & & & \\
\hline 20 & & & & & & & & & & & & & & & & & & \\
\hline $20 / \mathrm{SS}$ & & & & & & & & & & & & & & & & & & \\
\hline $20 / \mathrm{Pb}$ & & & & & & & & & & & & & & & & & & \\
\hline $20 / \mathrm{Cd}$ & & & & & & & & & & & & & & & & & & \\
\hline $20 / \mathrm{Pb}-\mathrm{Cd}$ & & & & & & & & & & & & & & & & & & \\
\hline
\end{tabular}

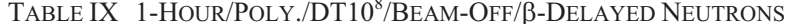

\begin{tabular}{|c|c|c|c|c|c|c|c|c|c|c|c|c|c|c|c|c|c|c|}
\hline \multirow{3}{*}{$\begin{array}{l}\text { Near } \\
\text { Shield } \\
\text { Case, } \\
\text { mass/ } \\
\text { shield }\end{array}$} & \multicolumn{9}{|c|}{$B=0.5 \mathrm{~s}^{-1}$} & \multicolumn{9}{|c|}{$B=5 s^{-1}$} \\
\hline & \multicolumn{3}{|c|}{$\mathrm{FP}=1 \sigma$} & \multicolumn{3}{|c|}{$\mathbf{F P}=2 \sigma$} & \multicolumn{3}{|c|}{$\mathbf{F P}=3 \sigma$} & \multicolumn{3}{|c|}{$\mathbf{F P}=1 \sigma$} & \multicolumn{3}{|c|}{$\mathbf{F P}=2 \sigma$} & \multicolumn{3}{|c|}{$\mathbf{F P}=3 \sigma$} \\
\hline & $\mid \begin{array}{c}\Xi \\
\dddot{a} \\
\dddot{0}\end{array}$ & $\begin{array}{c}\Xi \\
n \\
n \\
0\end{array}$ & $\Xi$ & 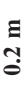 & 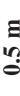 & $\Xi$ & $\stackrel{\Xi}{\tilde{z}}$ & בת & $\Xi$ & \begin{tabular}{l}
$\Xi$ \\
\multirow{3}{*}{}
\end{tabular} & 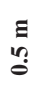 & $\Xi$ & \begin{tabular}{l}
$\mathbb{\Xi}$ \\
\multirow{T}{S}{}
\end{tabular} & 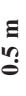 & $\Xi$ & \begin{tabular}{c}
$\Xi$ \\
\cline { 1 - 1 } \\
\hdashline
\end{tabular} & 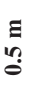 & $\Xi$ \\
\hline 1 & & & & & & & & & & & & & & & & & & \\
\hline $1 / \mathrm{SS}$ & & & & & & & & & & & & & & & & & & \\
\hline $1 / \mathrm{Pb}$ & & & & & & & & & & & & & & & & & & \\
\hline $1 / \mathrm{Cd}$ & & & & & & & & & & & & & & & & & & \\
\hline $1 / \mathrm{Pb}-\mathrm{Cd}$ & & & & & & & & & & & & & & & & & & \\
\hline 2 & & & & & & & & & & & & & & & & & & \\
\hline $2 / \mathrm{SS}$ & & & & & & & & & & & & & & & & & & \\
\hline $2 / \mathrm{Pb}$ & & & & & & & & & & & & & & & & & & \\
\hline $2 / \mathrm{Cd}$ & & & & & & & & & & & & & & & & & & \\
\hline $2 / \mathrm{Pb}-\mathrm{Cd}$ & & & & & & & & & & & & & & & & & & \\
\hline 5 & & & & & & & & & & & & & & & & & & \\
\hline $5 / \mathrm{SS}$ & & & & & & & & & & & & & & & & & & \\
\hline $5 / \mathrm{Pb}$ & & & & & & & & & & & & & & & & & & \\
\hline $5 / \mathrm{Cd}$ & & & & & & & & & & & & & & & & & & \\
\hline $5 / \mathrm{Pb}-\mathrm{Cd}$ & & & & & & & & & & & & & & & & & & \\
\hline 10 & & & & & & & & & & & & & & & & & & \\
\hline $10 / \mathrm{SS}$ & & & & & & & & & & & & & & & & & & \\
\hline $10 / \mathrm{Pb}$ & & & & & & & & & & & & & & & & & & \\
\hline $10 / \mathrm{Cd}$ & & & & & & & & & & & & & & & & & & \\
\hline $10 / \mathrm{Pb}-\mathrm{Cd}$ & & & & & & & & & & & & & & & & & & \\
\hline 20 & & & & & & & & & & & & & & & & & & \\
\hline $20 / \mathrm{SS}$ & & & & & & & & & & & & & & & & & & \\
\hline $20 / \mathrm{Pb}$ & & & & & & & & & & & & & & & & & & \\
\hline $20 / \mathrm{Cd}$ & & & & & & & & & & & & & & & & & & \\
\hline $20 / \mathrm{Pb}-\mathrm{Cd}$ & & & & & & & & & & & & & & & & & & \\
\hline
\end{tabular}

TABLE X 1-Hour/POLY./DD10 $0^{8}$ BEAM-OFF/ $/$-DELAYED GaMma RAYS.

\begin{tabular}{|c|c|c|c|c|c|c|c|c|c|c|c|c|c|c|c|c|c|c|}
\hline \multirow{3}{*}{$\begin{array}{l}\text { Near } \\
\text { Shield } \\
\text { Case, } \\
\text { mass/ } \\
\text { shield }\end{array}$} & \multicolumn{9}{|c|}{$B=0.5 s^{-1}$} & \multicolumn{9}{|c|}{$B=5 s^{-1}$} \\
\hline & \multicolumn{3}{|c|}{$\mathbf{F P}=1 \sigma$} & \multicolumn{3}{|c|}{$\mathbf{F P}=2 \sigma$} & \multicolumn{3}{|c|}{$\mathbf{F P}=3 \sigma$} & \multicolumn{3}{|c|}{$F P=1 \sigma$} & \multicolumn{3}{|c|}{$\mathbf{F P}=2 \sigma$} & \multicolumn{3}{|c|}{$F P=3 \sigma$} \\
\hline & $\begin{array}{c}\Xi \\
\tilde{\Xi} \\
\stackrel{\Xi}{ }\end{array}$ & \begin{tabular}{c}
$\Xi$ \\
$\vdots$ \\
\hdashline \\
\hdashline
\end{tabular} & $\Xi$ & 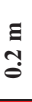 & $\begin{array}{c}\Xi \\
\vdots \\
0 \\
0\end{array}$ & $\Xi$ & $\begin{array}{l}\Xi \\
\\
\stackrel{\Xi}{0}\end{array}$ & 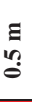 & $\Xi$ & 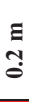 & 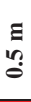 & $\Xi$ & 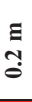 & $\begin{array}{c}\Xi \\
\vdots \\
0 \\
0 \\
0\end{array}$ & $=$ & 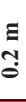 & & $\Xi$ \\
\hline 1 & & & & & & & & & & & & & & & & & & \\
\hline $1 / \mathrm{SS}$ & & & & & & & & & & & & & & & & & & \\
\hline $1 / \mathrm{Pb}$ & & & & & & & & & & & & & & & & & & \\
\hline $1 / \mathrm{Cd}$ & & & & & & & & & & & & & & & & & & \\
\hline 1/Pb-Cd & & & & & & & & & & & & & & & & & & \\
\hline 2 & & & & & & & & & & & & & & & & & & \\
\hline $2 / \mathrm{SS}$ & & & & & & & & & & & & & & & & & & \\
\hline $2 / \mathrm{Pb}$ & & & & & & & & & & & & & & & & & & \\
\hline $2 / \mathrm{Cd}$ & & & & & & & & & & & & & & & & & & \\
\hline $2 / \mathrm{Pb}-\mathrm{Cd}$ & & & & & & & & & & & & & & & & & & \\
\hline 5 & & & & & & & & & & & & & & & & & & \\
\hline $5 / \mathrm{SS}$ & & & & & & & & & & & & & & & & & & \\
\hline $5 / \mathrm{Pb}$ & & & & & & & & & & & & & & & & & & \\
\hline $5 / \mathrm{Cd}$ & & & & & & & & & & & & & & & & & & \\
\hline $5 / \mathrm{Pb}-\mathrm{Cd}$ & & & & & & & & & & & & & & & & & & \\
\hline 10 & & & & & & & & & & & & & & & & & & \\
\hline $10 / \mathrm{SS}$ & & & & & & & & & & & & & & & & & & \\
\hline $10 / \mathrm{Pb}$ & & & & & & & & & & & & & & & & & & \\
\hline $10 / \mathrm{Cd}$ & & & & & & & & & & & & & & & & & & \\
\hline $10 / \mathrm{Pb}-\mathrm{Cd}$ & & & & & & & & & & & & & & & & & & \\
\hline 20 & & & & & & & & & & & & & & & & & & \\
\hline $20 / \mathrm{SS}$ & & & & & & & & & & & & & & & & & & \\
\hline $20 / \mathrm{Pb}$ & & & & & & & & & & & & & & & & & & \\
\hline $20 / \mathrm{Cd}$ & & & & & & & & & & & & & & & & & & \\
\hline $20 / \mathrm{Pb}-\mathrm{Cd}$ & & & & & & & & & & & & & & & & & & \\
\hline
\end{tabular}




\section{Comparing Conceptual and Ideal Neutron Detectors}

The information presented in Table XI and Table XII illustrates how the FOM is impacted by switching between the conceptual ${ }^{3} \mathrm{He}$ detector, used in all of the above tables and figures, and an idealized detector. Considering neutron detection efficiency and detector surface area, the 'ideal' detectors represent a detector with absolute detection efficiency 3.9 times larger than the real detector. The information in these tables is for cement bulk shielding and irradiation with the $10^{8} \mathrm{n} \mathrm{s}^{-1}$ DT-ENG. Unlike in the prior tables, in these two tables data is presented from $0.2 \mathrm{~m}$ to $1 \mathrm{~m}$ in $0.1-\mathrm{m}$ increments. This higher spatial resolution is needed to illustrate the difference between the two detector types. A hint at the impact increasing the absolute detection efficiency can have on the time-to-detect FOM was also presented in Fig. 2, for a 5-times increase in efficiency.

For the cement case, and in general for these scenarios, the improved detector efficiency serves to reduce the FOM timeto-detect values by a factor of 2 to 4 . However, as illustrated in the figures above, the time-to-detect values grow exponentially for each case as the material is moved deeper into the shielding. Thus, improving detector efficiency in the range considered here serves primarily to reduce detection periods, for those cases that can be detected in the one-hour analysis, but doesn't manifest in dramatic improvements towards increasing the sensitive depth for detection. When signals are available to be measured the improved detectors help but if too-few fissions are being induced to generate a signal capable of exiting the shields with sufficient intensity over background levels, improving the efficiency can't help.

Table XI Cement/Pulsing/ $\beta$-Delayed Neutrons -- Concept Detector

\begin{tabular}{|c|c|c|c|c|c|c|c|c|c|c|c|c|c|c|c|c|c|c|c|c|c|}
\hline \multirow{3}{*}{$\begin{array}{l}\text { Near } \\
\text { Shield } \\
\text { Case, } \\
\text { mass/ } \\
\text { shield }\end{array}$} & \multicolumn{21}{|c|}{$B=0.5 s^{-1}$} \\
\hline & \multicolumn{10}{|c|}{$\mathbf{F P}=1 \sigma$} & \multicolumn{11}{|c|}{$F P=2 \sigma$} \\
\hline & \begin{tabular}{l}
$\Xi$ \\
\multirow{8}{*}{}
\end{tabular} & ? & e & & $\begin{array}{l}0 \\
? \\
0\end{array}$ & $\begin{array}{c}\Xi \\
\vdots \\
\stackrel{0}{0}\end{array}$ & $\begin{array}{c}\Xi \\
\stackrel{8}{\circ}\end{array}$ & 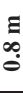 & $\Xi$ & 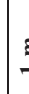 & & & $\begin{array}{l}\Xi \\
\cdots \\
0 \\
0\end{array}$ & & 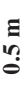 & $=$ & & & \begin{tabular}{c}
$\Xi$ \\
$\infty$ \\
\hdashline \\
\hdashline
\end{tabular} & $\begin{array}{l}\Xi \\
\vdots \\
\vdots \\
\end{array}$ & $\Xi$ \\
\hline 1 & & & & & & & & & & & & & & & & & & & & & \\
\hline $1 / \mathrm{SS}$ & & & & & & & & & & & & & & & & & & & & & \\
\hline $1 / \mathrm{Pb}$ & & & & & & & & & & & & & & & & & & & & & \\
\hline $1 / \mathrm{Cd}$ & & & & & & & & & & & & & & & & & & & & & \\
\hline $1 / \mathrm{Pb}-\mathrm{Cd}$ & & & & & & & & & & & & & & & & & & & & & \\
\hline 2 & & & & & & & & & & & & & & & & & & & & & \\
\hline $2 / \mathrm{SS}$ & & & & & & & & & & & & & & & & & & & & & \\
\hline $2 / \mathrm{Pb}$ & & & & & & & & & & & & & & & & & & & & & \\
\hline $2 / \mathrm{Cd}$ & & & & & & & & & & & & & & & & & & & & & \\
\hline $2 / \mathrm{Pb}-\mathrm{Cd}$ & & & & & & & & & & & & & & & & & & & & & \\
\hline 5 & & & & & & & & & & & & & & & & & & & & & \\
\hline $5 / \mathrm{SS}$ & & & & & & & & & & & & & & & & & & & & & \\
\hline $5 / \mathrm{Pb}$ & & & & & & & & & & & & & & & & & & & & & \\
\hline $5 / \mathrm{Cd}$ & & & & & & & & & & & & & & & & & & & & & \\
\hline $5 / \mathrm{Pb}-\mathrm{Cd}$ & & & & & & & & & & & & & & & & & & & & & \\
\hline 10 & & & & & & & & & & & & & & & & & & & & & \\
\hline $10 / \mathrm{SS}$ & & & & & & & & & & & & & & & & & & & & & \\
\hline $10 / \mathrm{Pb}$ & & & & & & & & & & & & & & & & & & & & & \\
\hline $10 / \mathrm{Cd}$ & & & & & & & & & & & & & & & & & & & & & \\
\hline $10 / \mathrm{Pb}-\mathrm{Cd}$ & & & & & & & & & & & & & & & & & & & & & \\
\hline 20 & & & & & & & & & & & & & & & & & & & & & \\
\hline $20 / \mathrm{SS}$ & & & & & & & & & & & & & & & & & & & & & \\
\hline $20 / \mathrm{Pb}$ & & & & & & & & & & & & & & & & & & & & & \\
\hline $20 / \mathrm{Cd}$ & & & & & & & & & & & & & & & & & & & & & \\
\hline $20 / \mathrm{Pb}-\mathrm{Cd}$ & & & & & & & & & & & & & & & & & & & & & \\
\hline
\end{tabular}

TABle XII Cement/Pulsing/ß-Delayed Neutrons -- IDEAL Detector

\begin{tabular}{|c|c|c|c|c|c|c|c|c|c|c|c|c|c|c|c|c|c|c|}
\hline \multirow{3}{*}{$\begin{array}{c}\text { Near } \\
\text { Shield } \\
\text { Case, } \\
\text { mass/ } \\
\text { shield }\end{array}$} & \multicolumn{18}{|c|}{$B=0.5 \mathrm{~s}^{-1}$} \\
\hline & \multicolumn{9}{|c|}{$F P=1 \sigma$} & \multicolumn{9}{|c|}{$\mathbf{F P}=2 \sigma$} \\
\hline & \begin{tabular}{l}
$\Xi$ \\
\multirow{2}{0}{}
\end{tabular} & $\begin{array}{c}\Xi \\
\vdots \\
ٌ\end{array}$ & $\begin{array}{l}\text { g } \\
\stackrel{+}{0}\end{array}$ & 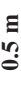 & 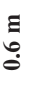 & $\begin{array}{l}\mathbb{a} \\
\stackrel{0}{0}\end{array}$ & 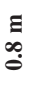 & $\begin{array}{l}\Xi \\
\text { } \\
\text { o }\end{array}$ & $\Xi$ & $\begin{array}{l}\mathbb{\Xi} \\
\stackrel{\text { g }}{\Xi}\end{array}$ & $\begin{array}{l}\Xi \\
\stackrel{a}{0} \\
\stackrel{2}{0}\end{array}$ & $\begin{array}{l}\Xi \\
\square \\
0\end{array}$ & 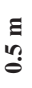 & $\begin{array}{c}\Xi \\
\vdots \\
\stackrel{0}{\circ}\end{array}$ & $\begin{array}{l}\Xi \\
\vdots \\
\dot{0}\end{array}$ & $\begin{array}{l}\Xi \\
\stackrel{\infty}{\circ}\end{array}$ & & $\Xi$ \\
\hline 1 & & & & & & & & & & & & & & & & & & \\
\hline $1 / \mathrm{SS}$ & & & & & & & & & & & & & & & & & & \\
\hline $1 / \mathrm{Pb}$ & & & & & & & & & & & & & & & & & & \\
\hline $1 / \mathrm{Cd}$ & & & & & & & & & & & & & & & & & & \\
\hline $1 / \mathrm{Pb}-\mathrm{Cd}$ & & & & & & & & & & & & & & & & & & \\
\hline 2 & & & & & & & & & & & & & & & & & & \\
\hline $2 / \mathrm{SS}$ & & & & & & & & & & & & & & & & & & \\
\hline $2 / \mathrm{Pb}$ & & & & & & & & & & & & & & & & & & \\
\hline $2 / \mathrm{Cd}$ & & & & & & & & & & & & & & & & & & \\
\hline $2 / \mathrm{Pb}-\mathrm{Cd}$ & & & & & & & & & & & & & & & & & & \\
\hline 5 & & & & & & & & & & & & & & & & & & \\
\hline $5 / \mathrm{SS}$ & & & & & & & & & & & & & & & & & & \\
\hline $5 / \mathrm{Pb}$ & & & & & & & & & & & & & & & & & & \\
\hline $5 / \mathrm{Cd}$ & & & & & & & & & & & & & & & & & & \\
\hline $5 / \mathrm{Pb}-\mathrm{Cd}$ & & & & & & & & & & & & & & & & & & \\
\hline 10 & & & & & & & & & & & & & & & & & & \\
\hline $10 / \mathrm{SS}$ & & & & & & & & & & & & & & & & & & \\
\hline $10 / \mathrm{Pb}$ & & & & & & & & & & & & & & & & & & \\
\hline $10 / \mathrm{Cd}$ & & & & & & & & & & & & & & & & & & \\
\hline $10 / \mathrm{Pb}-\mathrm{Cd}$ & & & & & & & & & & & & & & & & & & \\
\hline 20 & & & & & & & & & & & & & & & & & & \\
\hline $20 / \mathrm{SS}$ & & & & & & & & & & & & & & & & & & \\
\hline $20 / \mathrm{Pb}$ & & & & & & & & & & & & & & & & & & \\
\hline $20 / \mathrm{Cd}$ & & & & & & & & & & & & & & & & & & \\
\hline $20 / \mathrm{Pb}-\mathrm{Cd}$ & & & & & & & & & & & & & & & & & & \\
\hline
\end{tabular}

\section{DISCUSSION}

Time-to-detect figures, as presented in Section III.A, can provide a useful tool for assessing different signatures while a measurement is in progress. For example, referring to the $\beta$ delayed neutron data FOM in the top panel of Fig. 3, for bulkcement shielding without a near-shield, if a measurement goes for $100 \mathrm{~s}$ without a positive detection declaration, it becomes possible to rule out the existence of $1 \mathrm{~kg}$ of HEU (if one assumes no near shielding) at a distance of less than $\sim 35 \mathrm{~cm}$, to rule out $2 \mathrm{~kg}$ at less then $40 \mathrm{~cm}$, to rule out $5 \mathrm{~kg}$ at less than $50 \mathrm{~cm}$, to rule out less than $10 \mathrm{~kg}$ at less than $\sim 65 \mathrm{~cm}$, and to rule out less than $20 \mathrm{~kg}$ at $\sim 85 \mathrm{~cm}$. If a priori knowledge exists suggesting that the threat item being sought is greater then a certain mass, for example, then this type of templatematching aid could be used to abort a scan to allow an operator to move onto a new location or new item. Similarly, analysis of these types of plots indicates, for a particular case, which signature is most likely to 'win' the detection race.

The 1-hour results presented in Sections III.B and III.C provide the greatest insight into ability of ANI to detect HEU in shielding. Although space constraints prohibit presentation of the cement, wood, aluminum, and steel data in this same tabular formats above, the results for these materials generally fall in between the results for the no-shield case the polyethylene shield case. When die-away exists, detection of the prompt-fission neutrons in-between pulses of the ANI source is a strong signature. However, the results from this study clearly show that the die-away signature, by itself, is not a universal indicator. In non-moderating scenarios (e.g., no bulk shielding) or cases where a neutron-absorbing near shield is present the die-away signal is non-exisitent. 
The post-irradiation, $\beta$-delayed gamma-ray signature is moderately useful but the inability to reliably use the DT source for post-irradiation, high-energy gamma-ray measurements (due to the possible production of the interfering isotope ${ }^{16} \mathrm{~N}$ ) precludes exploiting this signature to its greatest potential.

As might be expected, the lower yield of the DD $10^{6}$ neutron source is far less capable for detection, in any shielded configuration, than the two $10^{8} \mathrm{n} \mathrm{s}^{-1}$ sources. The DD $10^{8}$ source produces slightly quicker detection times in the nonhydrogenous shields, at closer shielding depths than the DT source of equivalent intensity. However, the reduced penetration capability of the DD $10^{8}$ source reduces its detection of HEU at greater depths in a few cases. Overall, either source can be used effectively for the application. For logistical ease-of-use, a DD source of equivalent yield to the DT source would likely be preferred - if it existed.

Recent interest has grown towards exploring the use of high-intensity, single-shot pulsed radiation sources for active interrogation. Single-shot sources are desirable because of the dramatic improvement in signal versus background that can be achieved by colleting data only once, over a very short time frame. Indeed, examination of the analysis reported here indicates that improvements would be made by reducing the background intensity, as well as improving the uncertainty associated with determination of the background intensity. A challenge for operating in this mode, however, is the selection of detectors and data acquisition electronics that are capable of processing very high rate data. If a portable system capable of operating in this mode existed it could dramatically improve the performance of active interrogation.

\section{SUMMARY}

A modeling campaign has been performed to assess different methods for performing active neutron interrogation for detecting highly-shielded HEU in a variety of different bulk shields. This modeling examined different irradiations sources, different measured signatures, and the effects of engineered near-shields near the HEU. A constraint on this analysis was to limit consideration to approaches feasible for implementation as field-portable instrumentation. In this context, the currently-available DT-ENG neutron sources are far superior to current generation (lower yield) DD sources. Of the signatures studied, the most versatile signature for detecting shielded HEU is to measure the combined neutron emissions in-between pulses of the DT-ENG. Die-away neutrons are useful when available but cannot be reliably assumed to be present in any particular situation. Analysis of prompt-fission, high-energy neutrons while a DD-ENG is operating is a sound idea but in practice too large of a fraction of the induced fission-spectrum neutrons are downscattered below the energy cut-off as they exit most shields to yield a satisfactory measurement when shielding is present.

A result of this project is that a new suite of post-processing tools has been developed to take the output from Monte-Carlo simulation codes, such as MCNP and MCNPX, and generate time-evolving data sets representative of the type of data instruments generate when performing active interrogation measurements. This toolkit is equally capable of processing simulation results from other codes, including results from the
GEANT toolkit. Also, in addition to assessing the efficacy of ANI, as represented in this paper, the toolkit and methodology developed for this project may be used for assessing other active interrogation problems too.

\section{ACKNOWLEDGEMENTS}

We would like to thank Dr. Robert Runkle for his guidance during the early phases of this project. His suggestions and insights were greatly appreciated. We would also like to thank Dr. David Beach of the Office of Nonproliferation and Verification Research and Development (NA-22) of the National Nuclear Security Administration, United States Department of Energy, for his support of this project. We would also like to acknowledge the Office of Nonproliferation and International Security (NA-241) of the National Nuclear Security Administration, United States Department of Energy, for their support of a postdoctoral assistant for part of this project.

\section{REFERENCES}

[1] Doyle, J. E., Nuclear Safeguards, Security, and Nonproliferation, Oxford, U.K., Butterworth-Heinemann (2008) 511-512.

[2] Runkle, R. C., Chichester, D. L., and Thompson, S. J., "Rattling Nucleons: New Developments in Active Interrogation of Special Nuclear Material," Nucl. Inst. Meth. Phys. Res. A 663 (2012) 75-95.

[3] Fetter, S., Frolov, V. A., Miller, M., Mozley, R., Prilutsky, O. F., Rodionov, S. N., and Sagdev, R. Z., "Detecting Nuclear Warheads," Sci. Global Sec. 1 (1990) 225-302.

[4] Koonin, S., "Concealed Nuclear Weapons," Report JSR-03-130, JASON Study Group, MITRE Corporation, McLean, Va., December (2003).

[5] "Preventing and Defending Against Clandestine Nuclear Attack," Report of the Defense Science Board Task Force, Office of the Undersecretary of Defense for Acquisition, Technology, and Logistics, U.S. Department of Defense, Washington, D. C., June (2004)

[6] Gozani, T., "Active Nondestructive Assay of Nuclear Materials," Report NUREG/CR-0602, U.S. Nuclear regulatory Commission, Washington, D.C. (1981).

[7] "Detecting Nuclear and Radiological Materials," RS Policy Document 07/08, The Royal Society, London, U.K., March (2008).

[8] Moss, C. E., Hollas, C. L., McKinney, G. W., and Myers, W. L., "Comparison of Active Interrogation techniques," IEEE Trans. Nucl. Sci. 53 (2006) 2242-2246.

[9] Chichester, D. L. and Seabury, E. H., "Addressing Different Active Neutron Interrogation Signatures from Fissionable Material," IEEE Nucl. Sci. Symp. Conf. Rec., Orlando, Fla., Oct. 25 - 31 (2009 956-960.

[10] Swanekamp, S. N., et al., "An Analysis of Intense Pulsed Active Detection (IPAD) for the Detection of Special Nuclear Materials," IEEE Trans. Nucl. Sci. 58 (2011) 2047-2054.

[11] Gribkov, V., et al., "A Single-Shot Nanosecond Pulsed Technique for the Detection of Fissile Materials," J. Inst. 7 (2012) C07005.

[12] Tartaglione, A., Di Lorenzo, F., and Mayer, R. E., "Detection of ThermalInduced Prompt Fission Neutrons of Highly-Enriched Uranium: A Position Sensitive Technique," Nucl. Inst. Meth. Phys. Res. B 267 (2009) 24532456.

[13] Gozani, T., et al., "Differential Time of Flight (DTOF) Technique for Elemental Inspection," Proc. SORMA West 2012, Oakland, Calif., May 1417 (2012).

[14] Shaw, T. J., et al., "Improvement of SNM Detection Performance by Fusion of Data from Multiple Inspection Systems," IEEE Trans. Nucl. Sci. 56 (2009) 939-943.

[15] Gozani, T., Stevenson, J., and King, M. J., "Neutron Threshold Activation Detectors (TAD) for the Detection of Fissions," Nucl. Inst. Meth. Phys. Res. A 652 (2011) 334-337.

[16] Stevenson, J., et al., "LINAC Based Photofission Inspection System Employing Novel Detection Concepts," Nucl. Inst. Meth. Phys. Res. A 652 (2011) 124-128.

[17] King, M. J., et al., "Simultaneous Detection of Multiple Prompt and Delayed Fission Signatures Employing Liquid Scintillator with PSD," Proc. SORMA West 2012, Oakland, Calif., May 14-17 (2012). 
[18] Hausladen, P. A., et al., "Induced-Fission Imaging of Nuclear Material," Proc. $51^{\text {st }}$ Annual Meeting of Inst. Nucl. Mat. Manag., Baltimore, Md., July (2010).

[19] Cester, D., et al., "Special Nuclear Material Detection with a Mobile MultiDetector System," Nucl. Inst. Meth. Phys. Res. A 663 (2012) 55-63.

[20] Caffrey, A. J., et al., "Chemical Warfare Agent and High Explosive Identification by Spectroscopy of Neutron-Induced Gamma Rays," IEEE Trans. Nucl. Sci. 39 (1992) 1422-1426.

[21] Jones, J. L., et al., "Pulsed Photoneutron Interrogation: The GNT Demonstration System," Report WINCO-1225, Idaho National Engineering Laboratory, Idaho Falls, Id. (1994).

[22] Reber, E. L., et al., "Idaho Explosives Detection System," Nucl. Inst. Meth. Phys. Res. B 241 (2005) 738-742.

[23] Chichester, D. L. and Seabury, E. H., "Using Electronic Neutron Generators in Active Interrogation to Detect Shielded Fissionable Material," 56 (2009) 441-447.

[24] Ruddy, F. H., Flammang, R. W., and Seidel, J. G., "Low-Background Detection of Fission Neutrons Produced by Pulsed Neutron Interrogation," Nucl. Inst. Meth. Phys. Res. A 598 (2009) 518-525.

[25] Jordan, K. A., and Gozani, T., "Detection of ${ }^{235} \mathrm{U}$ in Hydrogenous Cargo with Differential Die-Away Analysis and Optimized Neutron Detectors," Nucl. Inst. Meth. Phys. Res. A 579 (2007) 388-390.

[26] Prussin, S. G., et al., "Comparison of Tests with $14-\mathrm{MeV}$ Neutrons to a Monte Carlo Model for Interrogation of Thick Cargos for Clandestine Fissionable Materials," Nucl. Inst. Meth. Phys. Res. A 569 (2006) 853-862.

[27] Lou, T. P. and Antolak, A., "Simulation of Cargo Container Interrogation by D-D Neutrons," Lawrence Berkeley National Laboratory, Berkeley, Calif. (2007).

[28] Lee, S. Y., Beddingfield, D. H., and Park, J., "Simulations for Active Interrogation of HEU in Cargo Containers," Report LA-UR-07-0714, Los Alamos National Laboratory, Los Alamos, N.M. (2007).

[29] King, M., et al., "Simulation Method for Photoneutron-Based Active Interrogation Systems," Nucl. Inst. Meth. Phys. Res. A 652 (2011) 129132.

[30] Chichester, D. L., et al., "Parametric Evaluation of Active Neutron Interrogation for the Detection of Shielded Highly Enriched Uranium in the Field," IEEE Nucl. Sci. Symp. Conf. Rec., Valencia, Spain, October 23-29 (2011) 964-971.

[31] "MCNP-A General Monte Carlo N-Particle Transport Code, Version 5," Report LA-UR-03-1987, Los Alamos National Laboratory, Los Alamos, N.M. (2003).

[32] "MCNPX - A General Purpose Monte Carlo Radiation Transport Code, Version 2.5.0, MCNPX User's Manual," Report LA-UR-05-0369, Los Alamos National Laboratory, Los Alamos, N.M. (2005).

[33] Private communication, Prof. Sara Pozzi, University of Michigan, Ann Arbor, Mich. (2012).

[34] Dietrich, D., et al., "A Kinematically Beamed, Low Enegy Pulsed Neutron Soruce for Actvie Interrogation," Nucl. Inst. Meth. Phys. Res. B 241 (2005) 826-830.

[35] Moss, C. E., et al., "Neutron Detectors for Actvie Interogation of Highly Enriched Uranium," IEEE Trans. Nucl. Sci. 51 (2004) 1677-1681.

[36] Slaughter, D. R., et al., "Optimized Performance for Neturon Interrogation to Detect SNM," Report UCRL-TR-228924, Lawrence Livermore Natioanl Labraotory, Livermore, Calif. (2007). 